\title{
Reduced Hsp70 and Glutamine in Pediatric Severe Malaria Anemia: Role of Hemozoin in Suppressing Hsp70 and NF- $\mathrm{kB}$ Activation
}

\author{
Prakasha Kempaiah, ${ }^{1,2}$ Karol Dokladny, ${ }^{2}$ Zachary Karim, ${ }^{1}$ Evans Raballah, ${ }^{3}$ John M Ong'echa, ${ }^{1,3}$ \\ Pope L Moseley, ${ }^{4,5}$ and Douglas J Perkins ${ }^{1,3}$
}

${ }^{1}$ Center for Global Health; ${ }^{2}$ Department of Internal Medicine, University of New Mexico Health Sciences Center, Albuquerque, New Mexico, United States of America; ${ }^{3}$ University of New Mexico/Kenya Medical Research Institute Laboratories of Parasitic and Viral Diseases, Kisumu, Kenya; ${ }^{4}$ Departments of Medicine and Biomedical Informatics, University of Arkansas for Medical Sciences, Little Rock, Arkansas, United States of America; and ${ }^{5}$ Novo Nordisk Foundation Center for Protein Research, Faculty of Health and Medical Sciences, Copenhagen University, Copenhagen, Denmark

\begin{abstract}
Severe malarial anemia (SMA; hemoglobin $(\mathrm{Hb})<5.0 \mathrm{~g} / \mathrm{dL}$ ) is a leading global cause of morbidity and mortality among children residing in Plasmodium falciparum transmission regions. Exploration of molecular pathways through global gene expression profiling revealed that SMA was characterized by decreased HSPA 7A, a heat shock protein 70 (Hsp70) coding gene. Hsp70 is a ubiquitous chaperone that regulates nuclear factor-kappa B (NF-kB) signaling and production of proinflammatory cytokines known to be important in malaria pathogenesis (for example, IL-1 $\beta$, IL-6 and TNF- $\alpha$ ). Since the role of host Hsp70 in malaria pathogenesis is unexplored, we investigated Hsp70 and molecular pathways in children with SMA. Validation experiments revealed that leukocytic HSP7O transcripts were reduced in SMA relative to nonsevere malaria, and that intraleukocytic hemozoin (PfHz) was associated with lower HSP70. HSP70 was correlated with reticulocyte production and Hb. Since glutamine (GIn) upregulates Hsp70, modulates NF-kB activation and attenuates overexpression of proinflammatory cytokines, circulating GIn was measured in children with malaria. Reduced GIn was associated with increased risk of developing SMA. Treatment of cultured peripheral blood mononuclear cells (PBMCs) with PfHz caused a time-dependent decrease in Hsp70 transcripts/protein and NF- $\mathrm{KB}$ activation. GIn treatment of PBMCs overcame PfHz-induced suppression of HSP70 transcripts/protein, reduced NF-kB activation and suppressed overexpression of IL-1 $\beta$, IL-6 and TNF- $\alpha$. These findings demonstrate that SMA is characterized by reduced intraleukocytic HSP70 and circulating GIn, and that PfHz-induced suppression of HSP70 can be reversed by GIn. Thus, GIn supplementation may offer important immunotherapeutic options for futures studies in children with SMA.
\end{abstract}

Online address: http://www.molmed.org

doi: $10.2119 / \mathrm{molmed} .2016 .00130$

\section{INTRODUCTION}

Plasmodium falciparum malaria remains one of the most common parasitic diseases around the world and is a leading cause of malaria-related deaths (1). The most common clinical form of

Address correspondence to Douglas J Perkins or Prakasha Kempaiah, Center for Global Health, Department of Internal Medicine, University of New Mexico Health Sciences Center, MSC 10-5550, Albuquerque, NM 87131-0001, USA. Phone: 505-272-6867/505-925-1020; Fax: 505-272-8441; E-mail: dperkins@salud.unm.edu or pkempaiah@salud.unm.edu. Submitted for Publication May 12, 2016; Accepted for Publication August 16, 2016; Published Online (www.molmed.org) August 30, 2016.

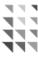

Feinstein Institute for Medical Research Northwell Health falciparum malaria, accounting for the majority of morbidity and mortality, is severe malarial anemia (SMA; hemoglobin $[\mathrm{Hb}]<5.0 \mathrm{~g} / \mathrm{dL}$ ), which occurs primarily in infants and young children residing in holoendemic $P$. falciparum

570 I KEMPAIAH Et AL. I MOL MED 22:570-584,2016 
to guide transcriptomic experiments in a subset of individuals with extreme (polarized) clinical phenotypes: mild malarial anemia (non-SMA, nonsevere disease; $\mathrm{Hb}, 8.0-10.9 \mathrm{~g} / \mathrm{dL} ; \mathrm{n}=50$, avg. $\mathrm{Hb}=10.8 \mathrm{~g} / \mathrm{dL}$ ) and SMA (severe disease; $\mathrm{Hb}<5.0 \mathrm{~g} / \mathrm{dL} ; \mathrm{n}=22$, avg. $\mathrm{Hb}=4.1 \mathrm{~g} / \mathrm{dL})$. These studies identified promising pathways for further studies on susceptibility to SMA, including the 70-kDa heat shock protein (Hsp70) pathway presented here. Considering the key role of Hsp70 as a chaperone, an immunogenic molecule and a protein that delivers and presents antigenic peptides (9), we reasoned that it is critically important for modulating the inflammatory milieu and, consequently, clinical outcomes in children with malaria.

We and others have shown that phagocytosis of $P$. falciparum-derived hemozoin (PfHz) by monocytes, macrophages and neutrophils causes dysregulation in inflammatory mediators that are associated with inefficient erythropoiesis and clinical outcomes in children with malaria, (6,10-13). Additional studies from our group and others have shown that cultured peripheral blood mononuclear cells (PBMCs) treated with physiological concentrations of $\mathrm{PfHz}$ have the ability to alter cytokines, chemokines and effector molecules that mimic observations during human falciparum infections $(6,14-16)$. Although the signaling pathways for $\mathrm{PfHz}$ require further characterization, nuclear factor-kappa B (NF-кB) appears to be a pivotal transcription factor in a number of inflammatory diseases, since it is a critical upstream regulator of gene expression due to the presence of consensus sequences in the promoter region of inflammatory mediators (16-18). In unstimulated conditions, $\mathrm{NF}-\kappa \mathrm{B}$ remains bound to its inhibitor, kappa B (IкB), in the cytoplasm as an inactive form (16-18). Following stimulation of cells, I $\kappa \mathrm{B}$ is phosphorylated by I $\mathrm{B}$ kinase to rapidly degrade and activate the NF- $\kappa \mathrm{B}$ dimer for translocation into the nucleus, where it binds to the enhancer regions on the promoter of target genes (16-18).
Aberrant NF- $\kappa \mathrm{B}$ activation has been associated with overabundant inflammatory events in arthritis, asthma, ischemia, septic shock and other autoimmune and inflammatory diseases $(19,20)$. Persistent inhibition of NF- $\mathrm{KB}$ activation has been linked to apoptosis, inappropriate immune cell development and delayed cell growth (19). Overexpression of Hsp70 in in vitro models inhibits nuclear translocation of $\mathrm{NF}-\kappa \mathrm{B}$ by preventing degradation of $\mathrm{I} \kappa \mathrm{B}$, thereby reducing the elevated production of proinflammatory mediators (20-22). Based on these studies and our transcriptomics experiment, we investigated the role of Hsp70 in modulating NF- $\kappa$ B and Hsp70 in malaria clinical outcomes.

L-glutamine (Gln) is the most abundant amino acid in the human body, stored in circulation and skeletal muscle, and is a modulator of Hsp70 protein through heat-shock factor 1 (HSF1) activation (23-27). In vitro and in vivo studies demonstrate that Gln upregulates the expression of HSP70 and attenuates overexpression of proinflammatory cytokines (i.e., IL-1 $\beta$, IL-6 and TNF- $\alpha$ ) (25-28). Gln appears to provide protective effects, since it is found to be low in the plasma and skeletal muscle of critically ill patients and is associated with poor clinical outcomes (29). Gln administration is associated with beneficial clinical outcomes in patients with acute illness, chronic inflammation, sepsis or inflammatory injury $(28,30,31)$. In addition, Gln supplementation in mice reduces the severity of septic shock by inhibition of proinflammatory cytokine release through enhanced Hsp70 expression (32).

In studies presented here, we measured HSP70 transcripts, the impact of naturally acquired PfHz on HSP70 expression, and circulating Gln levels in children with varying severity of falciparum malaria. Based on these findings, we then performed experiments in cultured primary human PBMCs to examine the molecular pathways underlying the relationship between $\mathrm{PfHz}, \mathrm{Hsp} 70$, and NF-кB on its target proinflammatory mediators (IL-1 $\beta$, IL- 6 and TNF- $\alpha$ ). Once these relationships were established, we determined the ability of Gln to overcome the Pf Hz-driven pathophysiological events.

\section{MATERIALS AND METHODS}

\section{Study Participants}

Children presenting at Siaya County Referral Hospital in western Kenya, a holoendemic $P$. falciparum transmission area, were recruited at their first hospital visit for the treatment of malaria $(3,33)$. After obtaining written informed consent from the children's parents or guardians, venipuncture blood samples $(<3.0 \mathrm{~mL})$ were collected from enrolled participants before any treatment interventions. Complete blood counts were determined using the Beckman Coulter $\mathrm{A}^{\mathrm{C}} \mathrm{T}$ diff2 ${ }^{\mathrm{TM}}$ (Beckman-Counter Corp.). Asexual malaria trophozoites in thick and thin peripheral blood smears and the reticulocyte production index (RPI) were determined according to our previous methods (4). Children were given appropriate treatment and supportive therapy according to the Kenyan Ministry of Health guidelines. Children with P. falciparum malaria were classified according to World Health Organization definitions: non-SMA ( $\mathrm{Hb} \geq 5.0 \mathrm{~g} / \mathrm{dL}$, with any density parasitemia) or SMA $(\mathrm{Hb}$ $<5.0 \mathrm{~g} / \mathrm{dL}$, with any density parasitemia) (34). The current study includes only children with $P$. falciparum parasitemia ( $n=144$, ages 3-36 months) without any coinfections (I.e., bacteremia or HIV-1).

\section{Sample Collection and Storage}

From each venous blood sample obtained $(<3.0 \mathrm{~mL})$, complete hematological measures, sickle-cell trait (HbAS), G6PD deficiency, $\alpha$-thalassemia, HIV-1 status and bacteremia were determined according to our published methods $(3,35)$. A portion of the blood was also centrifuged to separate the plasma, followed by snap freezing at $-80^{\circ} \mathrm{C}$ until use.

\section{Inflammatory Mediator and Glutamine Measurements}

Plasma samples were thawed and clarified by centrifugation $(13,148 g$ for $10 \mathrm{~min}$ ) before assaying. Circulating 
inflammatory mediator levels were determined using plasma with the Human Cytokine 25-plex Antibody Bead Kit according to the manufacturer's instructions. Plates were read on a Luminex ${ }^{\circledR}$ $100^{\mathrm{TM}}$ system and analyzed using the Bio-plex manager software (version IS.2.3). The selected analyte detection limits were: $15.0 \mathrm{pg} / \mathrm{mL}$ for IL-1 $\beta, 5.0$ $\mathrm{pg} / \mathrm{mL}$ for TNF- $\alpha$ and $3.0 \mathrm{pg} / \mathrm{mL}$ for IL-6. Gln concentrations were measured by a quantitative colorimetric method using the EnzyChrom ${ }^{\mathrm{TM}}$ glutamine assay kit (BioAssay Systems). The lower limit of detection for Gln was $23 \mu \mathrm{M} / \mathrm{L}$.

\section{Isolation and Culture of Peripheral Blood Mononuclear Cells}

PBMCs were isolated and cultured according to our previously described methods (12,36). Briefly, PBMCs $\left(2.5 \times 10^{6}\right.$ cells $/ \mathrm{mL}$ ) were cultured in 6-well plates under both physiological $\left(37^{\circ} \mathrm{C}\right)$ and heat shock treatment $\left(42^{\circ} \mathrm{C}\right)$ for $2 \mathrm{~h}$ prior to stimulation with lipopolysaccharide (LPS) (Escherichia coli LPS 0127B8, $200 \mathrm{ng} / \mathrm{mL}$ ) (Alexis Corp.) for $1 \mathrm{~h}$, followed by presence or absence of $\mathrm{PfHz}(10 \mu \mathrm{g} / \mathrm{mL})$ and Gln $(0.5,2.0$, and $4.0 \mathrm{mM})$ pretreatment for $30 \mathrm{~min}$ prior to adding $\mathrm{PfHz}$.

\section{Hemozoin Preparation}

Crude PfHz was isolated from mycoplasma-negative in vitro cultures of $P$. falciparum infected red blood cells as described previously (37). Briefly, P. falciparum (Pfd6 strain) infected RBCs were collected when parasitemia was $>5 \%$ with late-stage trophozoites and early schizonts as the predominant forms. Cultures were centrifuged at $1,308 \mathrm{~g}$ for $10 \mathrm{~min}$ and the pellet was resuspended in $40 \mathrm{~mL}$ of $0.01 \mathrm{M}$ phosphate-buffered saline (PBS; pH 7.2) containing 1\% saponin (Sigma) and incubated for $10 \mathrm{~min}$. Culture lysate was examined microscopically (in a hemocytometer) to ensure that the RBCs were completely lysed. Lysates were centrifuged at $13,148 g$ for $15 \mathrm{~min}$. The pellet was resuspended and washed $7 \times$ with PBS until the supernatant was clear, and then sonicated $2 \times$ to remove the lipids. The final pellet was dried at $40^{\circ} \mathrm{C}$ overnight, weighed and resuspended in filter-sterilized endotoxin-free $\mathrm{H}_{2} \mathrm{O}$ at $1.0 \mathrm{mg} / \mathrm{mL}$. Endotoxin level in the $\mathrm{PfHz}$ preparation was $<0.1 \mathrm{EU} / \mathrm{mL}$ as determined by the Limulus amebocyte lysate test (Thermo Fisher). Since $5.0 \mathrm{EU} / \mathrm{mL}$ is equal to $1 \mathrm{ng} / \mathrm{mL}$ of endotoxin, there was less than $0.02 \mathrm{ng} / \mathrm{mL}$ of endotoxin in the preparation.

\section{PCN and PCM Quantification}

Venous blood ( $<3.0 \mathrm{~mL}$ ) was collected from the study participants as stated earlier. Both thin and thick blood smears were prepared to determine the presence of parasites by counting the number of asexual stage parasites per 300 white blood cells. Measurements of pigment(or PfHz-) containing monocytes (PCMs) and pigment-containing neutrophils (PCNs) were determined on Geimsastained slides per previous methods (4). Enumeration of PCMs and PCNs was determined and expressed as the number of pigment-containing cells per microliter of blood.

\section{Transcriptome Analysis}

For global gene expression analyses, 72 samples were selected to represent "polarized extremes" of clinical phenotypes from a group of 1,643 children: mild malarial anemia (non-SMA, nonsevere disease; $\mathrm{Hb}, 8.0-10.9 \mathrm{~g} / \mathrm{dL} ; \mathrm{n}=50$, avg. $\mathrm{Hb}=10.8 \mathrm{~g} / \mathrm{dL}$ ) and SMA (severe disease; $\mathrm{Hb}<5.0 \mathrm{~g} / \mathrm{dL} ; \mathrm{n}=22$, avg. $\mathrm{Hb}=$ $4.1 \mathrm{~g} / \mathrm{dL})$. Children with coinfections (I.e., HIV-1 or bacteremia) were excluded from analysis since we have shown that these pathogens influence clinical disease outcomes $(6,7,35)$. Total RNA was isolated from WBC pellets collected on presentation at the hospital ( $\mathrm{d}$ 0) prior to any treatment interventions using the GITC method $(36,38)$. Following quality check and quantification, global gene expression profiling was performed using the Illumina ${ }^{\circledR}$ HumanHT-12 v4 beadchip covering $>47,000$ transcripts on the Illumina ${ }^{\circledR}$ iScan $S Q$ platform. The Illumina GenomeStudio $^{\circledR}$ was used to subtract the background signal from the transcript signal, which generated a list of 19,185 transcripts. Gene expression data underwent further selection with stepwise procedures using GeneSpring GX software (Agilent Technologies) to remove transcripts identified as having an "absent" expression for quality control.

\section{In Vitro Gene Expression Assays}

RNA was isolated from circulating white blood cells obtained from children with malaria using the GITC method $(36,38)$ and in vitro PBMC cultures using the RNEasy ${ }^{\circledR}$ mini kit (Qiagen) according to the manufacturer's instructions. From $1.0 \mu \mathrm{g}$ of total RNA, complementary DNA (cDNA) was prepared with the transcriptor first strand cDNA synthesis kit (Roche). For measurement of HSPA1A, $H S P A 1 B, I L-1 \beta, I L-6$ and TNF- $\alpha$ gene expression levels, $0.5 \mu \mathrm{g}$ of resulting cDNA was used for gene-specific TaqMan ${ }^{\circledR}$ qPCR assays. The constitutively expressed housekeeping gene $\beta$-actin was used as an endogenous control to normalize the target gene expression data in a quantitative gene expression assay on the StepOnePlus ${ }^{\mathrm{TM}}$ Real-Time PCR System (ABI).

\section{Immunoblot Assays}

Both floating and adherent cells from PBMC cultures were harvested and washed twice with cold PBS by centrifugation. For preparation of total crude lysates, cells $\left(4 \times 10^{6}\right)$ were lysed in $250 \mu \mathrm{L}$ of buffer containing of $125 \mathrm{mM}$ Tris- $\mathrm{HCl}$ (pH 6.8), 2\% SDS, 10\% glycerol, $50 \mathrm{mM}$ sodium phosphate, $1 \mathrm{mM}$ PMSF and protease inhibitor cocktail (Sigma). Resulting lysates were kept on ice for $10 \mathrm{~min}$ and centrifuged for $15 \mathrm{~min}$ at $10,000 \times g$ at $4^{\circ} \mathrm{C}$, and recovered supernatants were stored at $-80^{\circ} \mathrm{C}$ until use.

To quantify Hsp70 protein, samples were prepared by boiling supernatants in $4 \times$ Laemmli sample buffer (Bio-Rad Laboratories) for $5 \mathrm{~min}$ and loaded (50 $\mu \mathrm{g}$ of proteins) onto SDS-PAGE (4-20\% polyacrylamide gradient) gels. Following electrophoresis, proteins were electrotransferred to nitrocellulose membranes (Bio-Rad Laboratories), and subsequently blocked with $5 \%$ blotting 
grade nonfat dry milk (Bio-Rad Laboratories) in TBS/0.1\% Tween-20 at RT for $1 \mathrm{~h}$. Membranes were then probed with anti-Hsp70 antibody (Assay Designs) dissolved in fresh blocking buffer. Separate immunoblots were also generated by stripping the membranes to verify equal loading of lysate proteins using anti- $\beta$-actin antibody (for total protein) (Sigma). Immunoreactive proteins were identified using HRP-conjugated secondary antibodies (Cell Signaling) and a chemiluminescent reagent system.

To facilitate quantification of NF- $\kappa \mathrm{B}$ translocation into the nucleus, cytosolic and nuclear fractions were prepared from the freshly harvested cells using the nuclear extract kit (Active Motif) according the manufacturer's instructions. Equal amounts of protein were loaded on to $4-20 \%$ SDS-PAGE and probed with NF-кB (p65, C-term) antibody (GeneTex) dissolved in fresh blocking buffer. Separate immunoblots were generated by stripping the membranes to verify equal loading of lysate proteins using either anti- $\beta$-actin antibody (for total protein), or the integrity of the nuclear fraction was verified with anti-histone-H1 antibody (GeneTex). Immunoreactive proteins were identified using HRPconjugated secondary antibodies and a chemiluminescent reagent system.

\section{Data Analysis}

Differences in circulating inflammatory mediators, Gln and laboratory variables were determined using nonparametric Mann-Whitney U test for group comparisons, and Chi-square tests for differences in proportions between non-SMA and SMA groups (SPSS version 19.0 for Windows, SPSS Inc.). Logistic regression, controlling for age, gender and parasitemia, was used to examine association between Gln levels and SMA (SPSS version 19.0).). Global gene expression data was analyzed using the GeneSpring GX software (Agilent Technologies) and correlation tests were performed using the GraphPad Prism $5^{\circledR}$ (GraphPad Software Inc.) software. Analysis of variance (ANOVA) tests were used to compare gene expression levels across the groups. Bivariate analysis of normalized HSP70 $(1 A+1 B)$ gene expression between the two groups was performed using unpaired two-tailed $t$ test and presented as mean (SEM). The nonparametric Spearman's rank correlation co-efficient $(\rho)$ test was used to determine the association between circulating mediators and factors influencing SMA (i.e., $\mathrm{Hb}$ and reticulocyte production index). Densitometry quantification of immunoblots was performed using Image J software (Windows version of National Insititutes of Health'sImage, http://rsbweb.nih.gov/ij/download. $h t m l)$. The intensities are reported in arbitrary units (A.U.), obtained by subtracting the background value from the corresponding band's mean values determined after normalizing with housekeeping proteins (i.e., $\beta$-actin and histone-H1, respectively). Statistical significance for all analyses was set at $P \leq 0.050$.
All supplementary materials are available online at www.molmed.org.

\section{RESULTS}

\section{Clinical and Laboratory Characteristics of the Study Participants}

Parasitemic children $(\mathrm{n}=144)$ were stratified, based on $\mathrm{Hb}$ concentration, into two clinical categories: non-SMA $(\mathrm{Hb} \geq 5.0 \mathrm{~g} / \mathrm{dL})$ and SMA $(\mathrm{Hb}<5.0 \mathrm{~g} / \mathrm{dL})$ (34). Data are presented in Table 1. Children with SMA were significantly younger than those with non-SMA $(P=0.007)$. A number of hematological indices also differed between the two groups, with SMA characterized by elevated WBCs $(P=0.005)$ and monocytes $(P=0.037)$, and reduced granulocytes $(P=0.051)$ and platelets $(P=0.042)$. As expected based on the a priori grouping according to $\mathrm{Hb}$ levels, children with SMA had

Table 1. Clinical and laboratory characteristics of the study participants.

\begin{tabular}{|c|c|c|c|}
\hline Characteristic & Non-SMA $(\mathrm{Hb} \geq 5.0 \mathrm{~g} / \mathrm{dL})$ & $\mathrm{SMA}(\mathrm{Hb}<5.0 \mathrm{~g} / \mathrm{dL})$ & $P^{*}$ \\
\hline Number of subjects & 93 & 51 & $\mathrm{~N} / \mathrm{A}$ \\
\hline Age, months & $12.03(10.00)$ & $7.38(5.77)$ & $0.007^{a}$ \\
\hline Gender: male/female ** & $52 / 41$ & $22 / 28$ & $0.676^{\mathrm{b}}$ \\
\hline Glucose (mMol/L) & $4.90(1.00)$ & $5.10(1.00)$ & $0.484^{a}$ \\
\hline Temperature $\left({ }^{\circ} \mathrm{C}\right)$ & $37.40(2)$ & $37.30(1)$ & $0.818^{a}$ \\
\hline White blood cells $\left(\times 10^{9} / \mu \mathrm{L}\right)$ & $11.60(5.70)$ & $14.95(8.55)$ & $0.005^{a}$ \\
\hline Lymphocytes $\left(\times 10^{3} / \mu \mathrm{L}\right)$ & $49.00(23.05)$ & $51.05(12.55)$ & $0.128^{a}$ \\
\hline Monocytes $\left(\times 10^{3} / \mu \mathrm{L}\right)$ & $8.40(4.90)$ & $10.15(7.95)$ & $0.037^{a}$ \\
\hline Granulocytes $\left(x 10^{3} / \mu \mathrm{L}\right)$ & $42.10(26.00)$ & $37.90(16.80)$ & $0.051^{a}$ \\
\hline Hemoglobin ( $\mathrm{Hb}, \mathrm{g} / \mathrm{dL})$ & $7.90(5.05)$ & $4.20(1.10)$ & $<0.0001^{a}$ \\
\hline Hematocrit (Hct, \%) & $23.70(14.20)$ & $13.05(3.40)$ & $<0.0001^{a}$ \\
\hline Red blood cells $\left(\times 10^{6} / \mu \mathrm{L}\right)$ & $3.58(1.57)$ & $1.85(0.85)$ & $<0.0001^{a}$ \\
\hline Platelets $\left(\times 10^{3} / \mu \mathrm{L}\right)$ & $171(134)$ & $141(85)$ & $0.042^{a}$ \\
\hline Parasite denisty $(/ \mu \mathrm{L})$ & $24,991(54,895)$ & $23,661(62,758)$ & $0.928^{a}$ \\
\hline $\begin{array}{l}\text { Pigment-containing } \\
\text { monocytes (PCM), n (\%) }\end{array}$ & $45(48.39)$ & $39(76.47)$ & $0.001^{b}$ \\
\hline $\begin{array}{l}\text { Pigment-containing neutrophils } \\
(\mathrm{PCN}), \mathrm{n}(\%)\end{array}$ & $6(6.0)$ & $11(21.57)$ & $0.007^{b}$ \\
\hline $\mathrm{PCM}(/ \mu \mathrm{L})$ & $10.52(1.95)$ & $41.25(7.10)$ & $<0.0001^{\mathrm{c}}$ \\
\hline $\mathrm{PCN}(/ \mu \mathrm{L})$ & $0.34(0.14)$ & $5.31(1.88)$ & $<0.0001^{\mathrm{C}}$ \\
\hline $\begin{array}{l}\text { Reticulocyte production } \\
\text { index }<2.0\end{array}$ & $58(62.37)$ & $47(92.16)$ & $<0.0001^{a}$ \\
\hline
\end{tabular}

Parasitemic children ( $\mathrm{n}=144$ ) were stratified into non-SMA (i.e., $\mathrm{Hb} \geq 5.0 \mathrm{~g} / \mathrm{dL}$ ) and SMA (i.e., $\mathrm{Hb}<5.0 \mathrm{~g} / \mathrm{dL}$ ) (34). Data presented are medians (interquartile range, IQR), unless otherwise stated. aStatistical significance determined by Mann-Whitney U test. 'bStatistical significance determined by the Chi-square analysis. 'Statistical significance determined by independent samples $t$ test. 
lower $\mathrm{Hb}$ concentrations $(P<0.0001)$, hematocrit $(P<0.0001)$ and RBC counts $(P<0.0001)$. Of note, peripheral malaria parasite density did not differ between the two groups $(P=0.928)$. Examination of circulating PfHz-containing leukocytes revealed that children with SMA had a higher percentage of PCM $(P=0.001)$ and PCN $(P=0.007)$, as well as elevated levels of $\mathrm{PCM} / \mu \mathrm{L}(P<0.0001)$ and $\mathrm{PCN} / \mu \mathrm{L}$ $(P<0.0001)$. Children with SMA also had a higher percentage of inefficient erythropoiesis, characterized by RPI $<2.0$ $(P<0.0001)$. Taken together, these results illustrate that children with SMA have distinct hematological profiles in the context of comparable peripheral parasite burden and enhanced phagocytosis of $\mathrm{PfHz}$ by circulating neutrophils and monocytes, as we have previously shown $(4,6,39)$.

\section{Ex Vivo HSP70 Gene Expression in Children with Malaria}

To identify promising gene pathways that could potentially mediate the

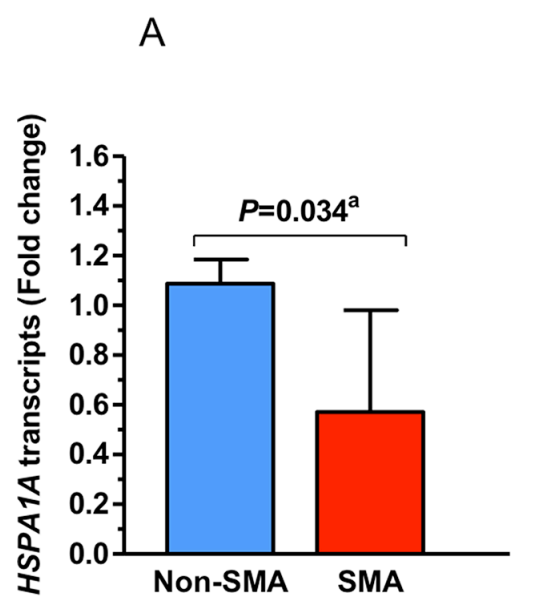

clinical outcomes in children with severe malaria, global gene expression was performed with the Illumina ${ }^{\circledR}$ HumanHT-12 v4 beadchip array. As mentioned above, the transcriptomics experiments utilized a subset of malaria-infected individuals with polarized clinical phenotypes to enhance discovery of potentially important signals by comparing extreme groups and removing ambiguous signals that may overlap in children with non-SMA versus SMA. Among a number of important signals that emerged from the transcriptomics experiments, children with SMA had significantly lower HSPA1A transcripts than children with mild malaria (non-SMA, $P=0.034$, Figure 1A). Based on these results and the importance of Hsp70 in innate immunity $(9,21,22,40-42)$, we validated gene expression profiles for HSPA1A and also measured HSPA1B (which was not present in the transcriptomics array). This approach allowed us to account for total HSP70 expression (HSPA1A and HSPA1B) in the

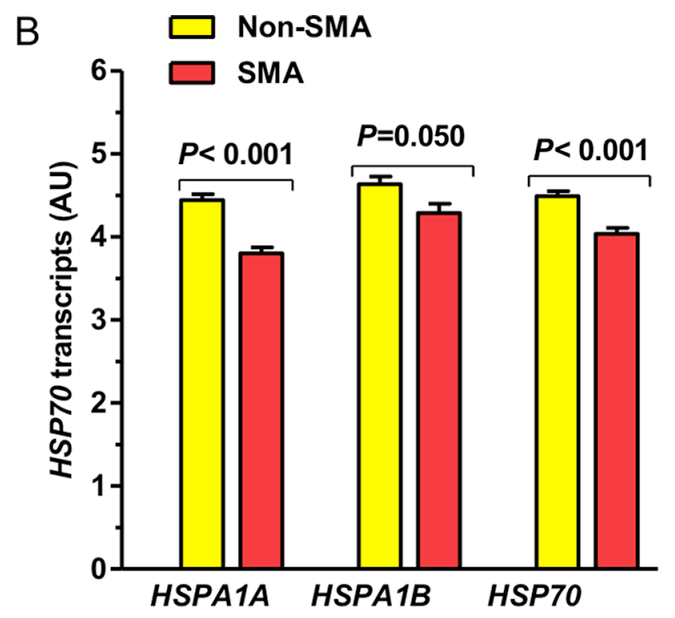

non-SMA and SMA groups. Gene expression levels for HSPA1A and HSPA1B were significantly lower in the SMA group $(P<0.001$ and $P=0.050$, respectively), as were the combined $H S P A 1 A / 1 B$ data representing total HSP70 transcript levels $(P<0.001$, Figure 1B).

Since we have shown that levels of intraleukocytic $\mathrm{PfHz}$ are strongly associated with circulating inflammatory mediator production and suppression of intracellular proteins that regulate immune responses in children with falciparum malaria $(36,39,43)$, we reasoned that phagocytosis of malarial pigment may also be an important mechanism through which Hsp70 is downregulated. As such, HSP70 gene expression was stratified according to absence/presence of $\mathrm{PfHz}$ in circulating monocytes (PCMs) and neutrophils (PCNs), respectively. Presence of naturally acquired intracellular $\mathrm{PfHz}$ in both monocytes and neutrophils was associated with significantly lower HSP70 transcript levels $(P=0.010$ and $P=0.019$,

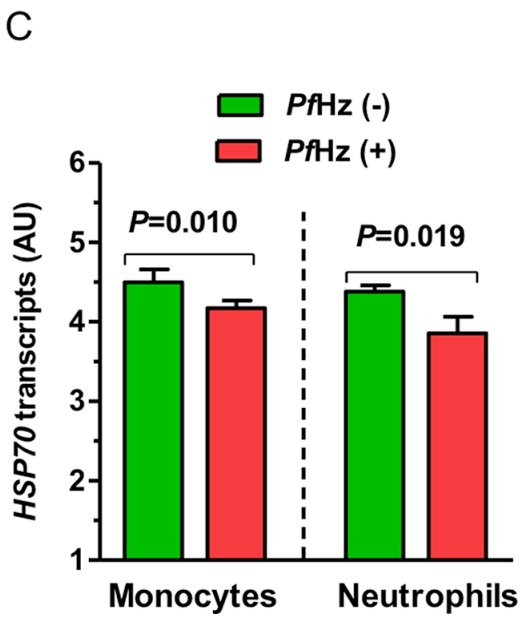

Figure 1. HSP70 gene expression in children with malaria. (A) Parasitemic children $(\mathrm{n}=72)$ were categorized according to "polarized" phenotypic clinical categories of non-SMA (Hb 8.0-10.9 g/dL, $n=50$ ) and SMA ( $\mathrm{Hb}<5.0 \mathrm{~g} / \mathrm{dL}, \mathrm{n}=22$ ). Global gene expression profiling was performed on total RNA isolated from WBCs using the lllumina ${ }^{\circledR}$ HumanHT-12 v4 beadchip array covering $>47,000$ transcripts. Panel A shows HSPA 1A gene expression analysis. "Bivariate analysis of HSPA lA gene expression between two groups was performed using unpaired t test and presented as mean (SEM). (B) HSPA IA/1B and HSP70 gene expression analysis using qRT-PCR on WBCs collected from parasitemic children $(n=73)$ stratified into non-SMA $(H b \geq 5.0 \mathrm{~g} / \mathrm{dL}, \mathrm{n}=52)$ and SMA $(\mathrm{Hb}<5.0 \mathrm{~g} / \mathrm{dL}, \mathrm{n}=21)$. The cyclophilin-A gene was used as an endogenous control to normalize expression. Bivariate analysis of normalized HSPA IA/1B gene expression (arbitrary units, $A U$ ) between two groups was performed using unpaired two-tailed t test and presented as mean (SEM). (C) HSP70 gene expression in $\mathrm{PfHz}$-containing monocytes and neutrophils. Bivariate analysis of normalized HSP70 $(1 A+1 B)$ gene expression between PfHz-containing monocytes and neutrophils. PfHz (-) monocytes $(n=22)$, PfHz (+) monocytes $(n=51)$; PfHz(-) neutrophils $(n=65)$, and PfHz $(+)$ neutrophils $(n=8)$. Bivariate analysis of normalized HSPA IA/IB gene expression (arbitrary units, $A U$ ) between two groups was performed using unpaired two-tailed $t$ test and presented as mean (SEM). 
respectively, Figure $1 \mathrm{C}$ ), suggesting that phagocytosis of $\mathrm{PfHz}$ during acute infection may be an important mechanism for suppression of Hsp70. In addition, other heat-shock responses were examined by quantifying the expression of heat-shock protein 90 (HSP90), a gene with similar functions that also protects against cellular stress and acts as a molecular chaperone. The transcriptomics experiment revealed that children with non-SMA had two-fold higher HSP90 transcripts levels than the SMA group $(P=0.106$, Supplementary Figure S1).

\section{Relationship between HSP70 Gene Expression and Measures of Anemia in Children with Malaria}

Next, we sought to determine if there was an association between HSP70 and markers of anemia in children with malaria. One important mechanism for severe anemia in children with malaria is altered innate immune response that causes inefficient erythropoiesis, which in turn contributes to anemia $(4,6,7,44)$. Although not previously explored as part of the host immune response to malaria, Hsp70 is known to regulate downstream inflammatory cytokines and effector molecules (42) that are important in malaria pathogenesis (6). As such, the relationship between HSP70 transcripts, $\mathrm{RPI}$ and $\mathrm{Hb}$ concentrations were examined. Our previous studies have shown that ineffective erythropoiesis, represented by determining RPI, is an important mechanism for promotion of anemia in children with malaria (4). As shown in Figure 2, there was a positive correlation between HSP70 transcripts and both RPI ( $\rho=0.208, P=0.002$, Figure 2A) and Hb concentrations $(\rho=0.182, P=0.006$, Figure $2 \mathrm{~B}$ ). These results suggest that reduced HSP70 expression in children with malaria may play an important role in promoting inefficient erythropoiesis that culminates in enhanced anemia.

\section{Effect of Hemozoin on Hsp70}

Results obtained in children with malaria demonstrated that SMA is characterized by reduced HSP70 transcripts in peripheral blood, and that phagocytosis of $\mathrm{PfHz}$ by circulating leukocytes may be an important event in causing suppression of Hsp70. Although previous studies showed that malarial pigment increases expression of Hsp27, a chemokine-related heat-shock protein with antiapoptotic properties (14), the effect of PfHz on Hsp70 has not been reported. Based on this previous finding and results presented here in children with malarial anemia, we examined the time-dependent (i.e., 2, 8, 24 and $48 \mathrm{~h}$ ) effect of physiological concentrations of $\mathrm{PfHz}(10 \mu \mathrm{g} / \mathrm{mL})$ (37) on Hsp70 transcripts and protein in cultured PBMCs. In addition, since heat-shock treatment $\left(42^{\circ} \mathrm{C}\right)$ induces overexpression of Hsp70 (45), the time-dependent effects of $\mathrm{PfHz}$ on Hsp70 were examined under both physiological $\left(37^{\circ} \mathrm{C}\right)$ and heat-shock conditions ( $2 \mathrm{~h}$ pretreatment exposure). Because it is a challenge to determine decreased gene expression in response to $\mathrm{PfHz}$ without first inducing expression of the gene(s) of interest that are often expressed at low levels in PBMCs from noninfected individuals, cells were pretreated with LPS for $1 \mathrm{~h}$. Based on the lack of in vivo priming in healthy individuals, LPS can be used to generate higher basal levels of genes, particularly those that are downregulated by pathogen products, so that in vitro investigations can be performed from blood isolated from healthy donors $(22,36,46,47)$. Addition of $\mathrm{PfHz}$ reduced LPS-induced expression of HSP70 transcripts in a time-dependent manner under both physiological and heat-shock conditions (Figure 3A). To confirm that changes in HSP70 transcripts corresponded with functional changes in Hsp70 protein,
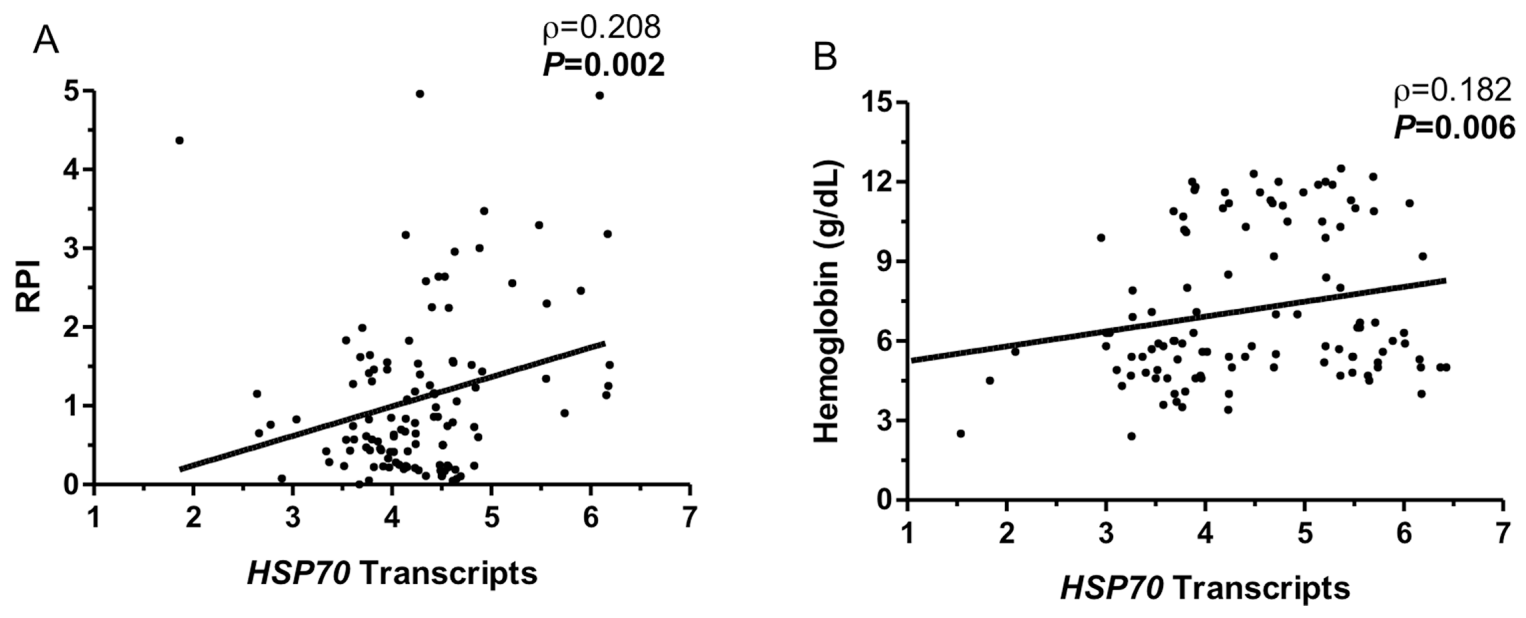

Figure 2. Relationship between HSP70 transcripts and indicators of anemia (RPI and Hb). HSP70 (1A + lB) gene expression was measured using WBCs collected from parasitemic children $(n=73)$. The cyclophilin-A gene was used as an endogenous control to normalize the gene expression data in qRT-PCR assays. Nonparametric Spearman's rank correlation coefficient test was used to determine the relationship between HSP70 transcripts levels and (A) reticulocyte production index (RPI) and (B) hemoglobin levels (g/dL). 

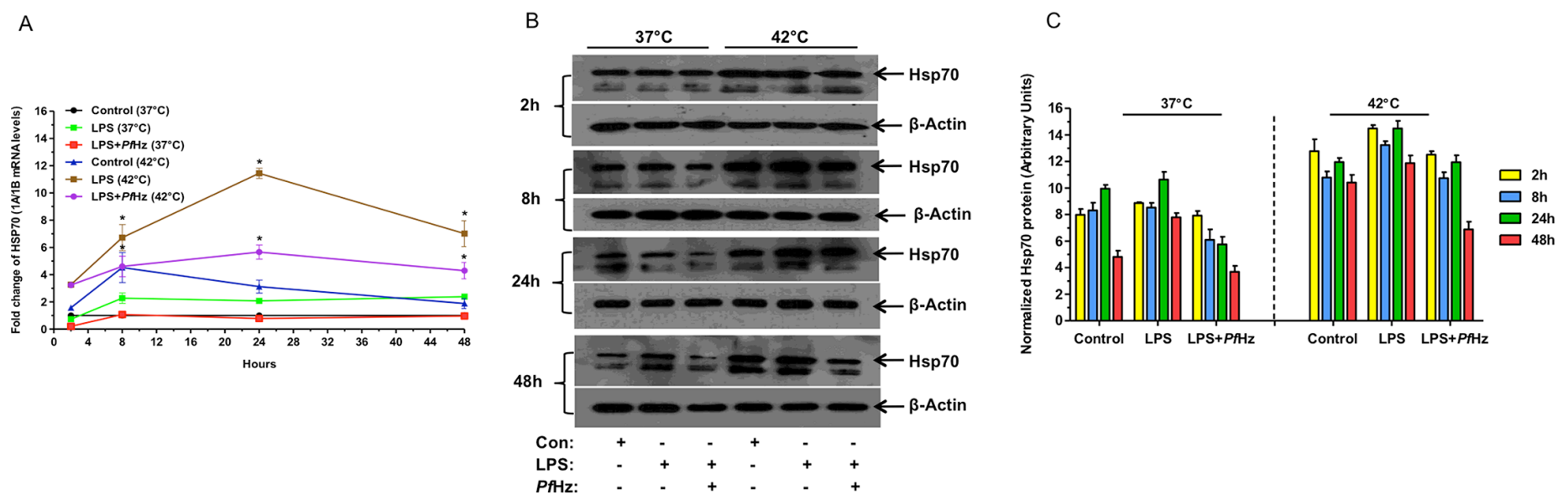

Figure 3. Effect of PfHz on HSP70 expression. Peripheral blood mononuclear cells $\left(2.5 \times 10^{6}\right)$ were incubated for $2 \mathrm{~h}$ at either $37^{\circ} \mathrm{C}$ (physiological) or $42^{\circ} \mathrm{C}$ (heat shock treatment) and stimulated with LPS for $1 \mathrm{~h}$. Cells were then treated with PfHz (10 $\left.\mu \mathrm{g} / \mathrm{mL}\right) \mathrm{and}$ incubated for different time points ( 2 to $48 \mathrm{~h}$ ). (A) Total RNA was isolated and gene expression analysis by qRT-PCR was performed to quantify the HSP7O $(7 A+7 B)$ transcripts, using TaqMan ${ }^{\circledR}$ gene expression assays. $\beta$-actin was used as an endogenous control to normalize the data by the $\Delta \Delta$ CT method. Data represent average of individuals $(n=3)$ with each condition performed in triplicate (error bars represent SEM). * indicates $P<0.05$ (one-way ANOVA) relative to control conditions at the given temperature. (B) Cell lysates were prepared after harvesting cells from identical experiments at the stipulated time points, and equal amounts of protein were loaded on 4-20\% SDS-PAGE to determine the Hsp70 protein levels by immunoblotting. (C) Densitometry analysis was performed to quantify intensity of production $(n=3)$; error bars represent SEM. Data shown after normalizing Hsp70 relative to $\beta$-actin.

the time-dependent effect of $\mathrm{PfHz}$ on protein levels was determined. Consistent with the gene expression profiling, PfHz decreased LPS-induced Hsp70 protein in a time-dependent fashion under physiological and heat-shock conditions (Figures 3B and C). These results provide support for the ex vivo measurements of HSP70 transcripts in children with malaria, showing that the presence of intraleukocytic $\mathrm{PfHz}$ is associated with significantly reduced HSP70 (Figure 1C). In addition, as shown in Supplementary Figure 2, PfHz alone induced a slight downregulation of HSP70 gene expression, which was less pronounced than that observed in LPS-treated cells that were primed for $1 \mathrm{~h}$ prior to addition of $\mathrm{PfHz}(P=0.301)$, suggesting that the effect of $P f H z$ on HSP70 is not unique to LPS.

\section{Effect of Hemozoin on NF-kB Activation}

Previous in vitro studies showed that hemozoin causes increased translocation of NF- $\kappa \mathrm{B}$ into the nucleus and enhanced expression of proinflammatory cytokines
'(14,37,48,49). Conversely, overproduction of Hsp70 leads to reduced NF- $\kappa B$ signaling and decreased proinflammatory cytokine production $(50,51)$. The link between $\mathrm{PfHz}, \mathrm{Hsp} 70$ and NF-кB translocation into the nucleus, however, has not been established. As such, cultured PBMCs were stimulated with $\mathrm{PfHz}$ under identical conditions as outlined above for the Hsp70 experiments, and the timedependent translocation of NF-кB into the nucleus was examined. As shown in Figures 4A and B, LPS induced translocation of NF- $\kappa \mathrm{B}$ protein into the nucleus as early as $2 \mathrm{~h}$ and increased thereafter at both $37^{\circ} \mathrm{C}$ and $42^{\circ} \mathrm{C}$. Importantly, the addition of $\mathrm{PfHz}$ caused further enhancement of NF- $\kappa \mathrm{B}$ translocation into the nucleus, with peak expression at $8 \mathrm{~h}$ under physiological $\left(37^{\circ} \mathrm{C}\right)$ and heat-shock conditions $\left(42^{\circ} \mathrm{C}\right.$, Figures $4 \mathrm{~A}$ and $\mathrm{B})$. Consistent with the fact that heat-shock treatment increases Hsp70 and thereby reduces NF- $\kappa B$ translocation into the nucleus (20-22), the effect of $\mathrm{PfHz}$ on $\mathrm{NF}-\kappa \mathrm{B}$ at $42^{\circ} \mathrm{C}$ was not as pronounced as that observed at $37^{\circ} \mathrm{C}$ (Figures $4 \mathrm{~A}$ and $\mathrm{B}$ ).

\section{Circulating Glutamine Levels in Children with Malaria}

Low plasma Gln levels are associated with poor clinical outcomes, shock and increased risk of mortality in hospitalized patients $(30,31)$. In addition, low plasma Gln concentrations $(<420$ $\mu \mathrm{mol} / \mathrm{L}$ ) are an independent risk factor for mortality and multiple organ failure in critically ill adults and children, respectively $(30,52)$. As such, we measured circulating Gln levels in children with non-SMA ( $\mathrm{n}=37)$ and SMA $(\mathrm{n}=31)$. Gln levels were significantly reduced in children with SMA (484 (142-920)) compared with those with non-SMA (1361 (182-1816), $P<0.0001$; Figure 5A).

To further explore the relationship between plasma Gln levels and SMA, children were stratified into two groups based on low plasma Gln concentrations: $<420 \mu \mathrm{mol} / \mathrm{L}(\mathrm{n}=20)$ and $>420 \mu \mathrm{mol} / \mathrm{L}$ $(\mathrm{n}=48)$. Logistic regression analysis, controlling for age, gender and parasitemia, revealed that plasma Gln levels $<420 \mu \mathrm{mol} / \mathrm{L}$ were associated with a seven-fold higher risk of developing SMA (OR 7.31; 95\% CI 1.82-29.41; 
A

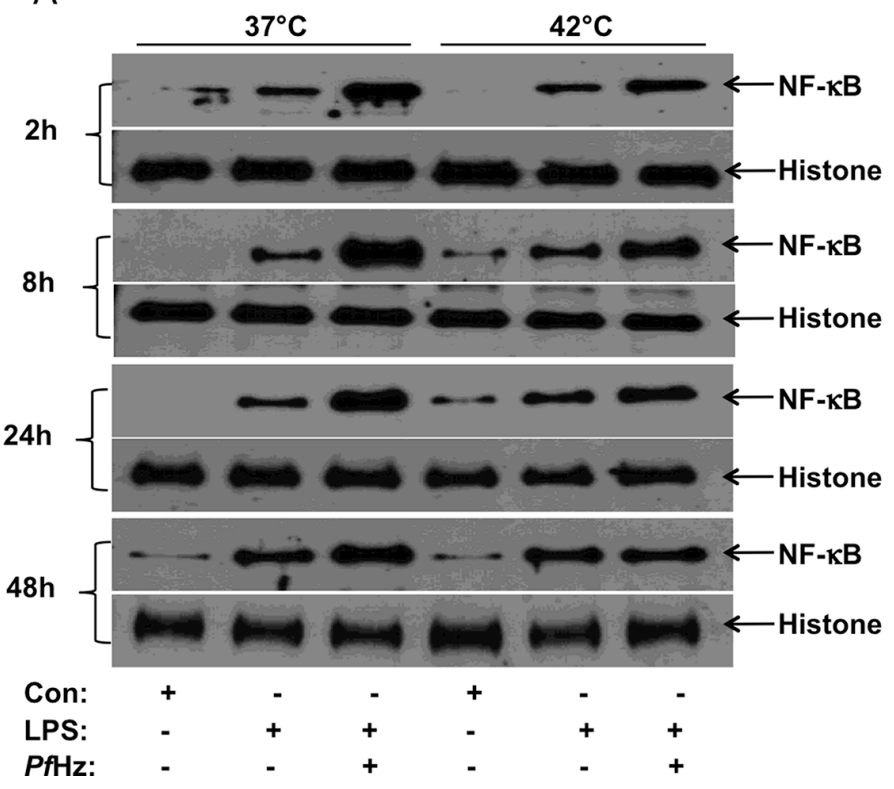

B

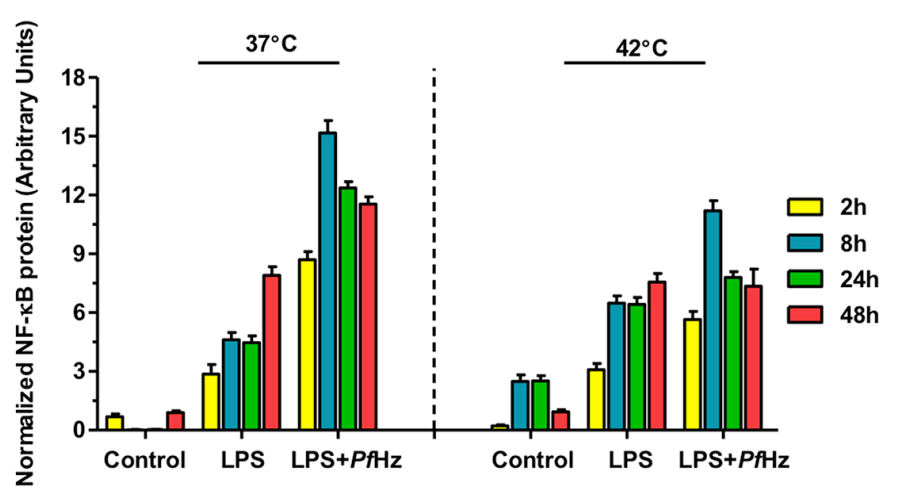

Figure 4. Effect of PfHz and heat shock treatment on NF-kB translocation into the nucleus. Peripheral blood mononuclear cells $\left(2.5 \times 10^{6}\right)$ were incubated for $2 \mathrm{~h}$ at either $37^{\circ} \mathrm{C}$ (physiological) or $42^{\circ} \mathrm{C}$ (heat shock treatment) and stimulated with LPS for $1 \mathrm{~h}$. Cells were treated with $\mathrm{PfHz}(10 \mu \mathrm{g} / \mathrm{mL}$ ) and incubated for different time points (2 to $48 \mathrm{~h}$ ). (A) Nuclear extracts were prepared after harvesting cells and equal amounts of protein were loaded on 4-20\% SDS-PAGE to determine the amount of nuclear translocated NF-kB by immunoblotting. In addition, a nuclear marker (histone protein) was quantified to account for protein loading (control). (B) Densitometry analysis after normalizing the respective bands against histone $(n=3)$; error bars represent SEM.

A

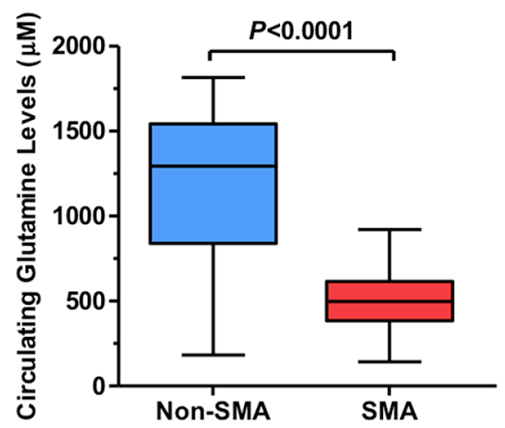

B

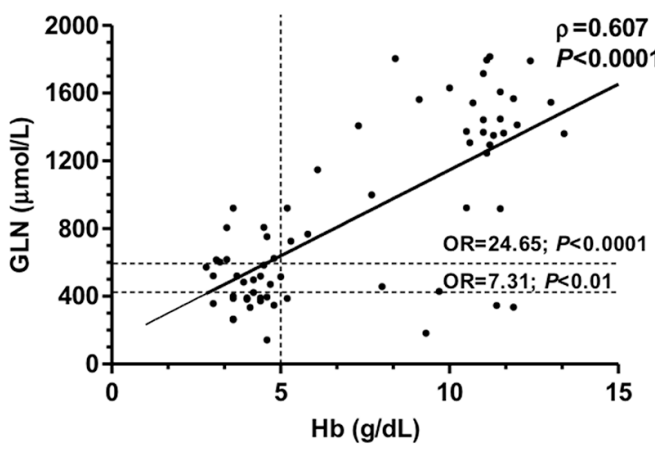

C

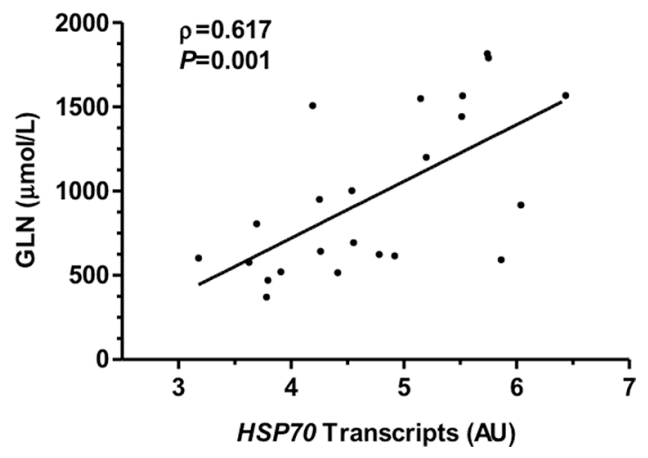

Figure 5. Circulating glutamine levels and HSP70 transcripts in children with malaria. (A) Glutamine plasma concentrations (mmol/L) in children stratified into non-SMA ( $\mathrm{Hb} \geq 5.0 \mathrm{~g} / \mathrm{dL}, \mathrm{n}=37$ ) and SMA ( $\mathrm{Hb}<5.0 \mathrm{~g} / \mathrm{dL}, \mathrm{n}=31)$ ). Box plots depict the data, where the box represents the interquartile range, the line through the box is the median, and whiskers illustrate the 10th and 90th percentiles. Significance determined by Mann-Whitney U test. (B) Relationship between circulating glutamine (GLN) and hemoglobin (Hb) levels ( $\mathrm{g} / \mathrm{dL}$ ) determined using Spearman's rank correlation test. Also shown are lines indicating cutoff values for SMA (Hb $<5.0 \mathrm{~g} / \mathrm{dL}$ ) relative to $\mathrm{GLN}$ levels above and below $420 \mathrm{mmol} / \mathrm{L}(<420, \mathrm{n}=20$ and $>420, \mathrm{n}=48$ ), and referenced according to 2 STD below the mean $(<598 \mathrm{mmol} / \mathrm{L}, \mathrm{n}=29$ and $>598, n=39$ ). Logistic regression analyses were used to determine the relationship between the GLN cutoff values and susceptibility to SMA. (C) Relationship between plasma GLN and HSP70 transcripts levels $(n=33)$ was determine by Spearman's rank correlation test.

$P<0.01$; Figure 5B). Although the commonly used adult cutoff value of $420 \mu \mathrm{mol} / \mathrm{L}$ has been validated in one pediatric cohort (53), we took an unbiased approach to represent the distribution within the population and stratified plasma Gln concentrations as two standard deviations (SDs) below the mean $(2$ SDs from mean $=598)$. Logistic 
regression analyses controlling for identical covariates demonstrated that children with plasma Gln concentrations $<598 \mu \mathrm{mol} / \mathrm{L}$ $(n=29)$ had a 24-fold higher risk of developing SMA (OR 24.65; 95\% CI 5.47-111.15; $P<0.0001$; Figure 5B). Thus, low plasma Gln levels in children with malaria are associated with a highly significant risk for developing SMA.

Since Gln is known to increase HSP70 gene expression $(23,25-28)$, the relationship between circulating Gln and HSP70 transcripts was determined in children with malaria. As shown in Figure 5C, there was a positive correlation between circulating Gln and HSP70 transcripts $(\rho=0.617, P=0.001)$.

\section{Effect of Glutamine on Hemozoin- Induced Suppression of Hsp70}

Since circulating levels of Gln were significantly reduced in children with SMA (see Figure 5A), and Gln improves clinical outcomes in acute illness and injury through increasing Hsp70 expression, an event that attenuates NF- $\kappa B$ translocation to nucleus $(28,41,54)$, we determined whether the addition of Gln could overcome PfHz-induced suppression of Hsp70 and activation of NF- $\kappa$ B. As shown in Figure 6A, treatment of cells with Gln dose-dependently (0.5, 2.0 and $4.0 \mathrm{mM}$ ) enhanced HSP70 transcripts in the presence of $\mathrm{PfHz}$ throughout the time-course experiment $(P<0.05$ for Gln treatments at all time points versus LPS and PfHz). To confirm that the transcriptional changes induced by Gln were also present at the protein level, Hsp70 protein expression was determined at $24 \mathrm{~h}$. Consistent with the mRNA experiments, phagocytosis of $\mathrm{PfHz}$ reduced Hsp70 production and treatment with Gln dose-dependently rescued the inhibitory effect of $\mathrm{PfHz}$ on Hsp70

(Figures 6B and C). Thus, treatment with Gln can overcome PfHz-induced suppression of Hsp70. To confirm that the observed effects were not unique to LPStreated conditions, additional experiments were performed using Gln and $\mathrm{PfHz}$ alone and in combination, without LPS stimulation. The results show that $\mathrm{PfHz}$ alone had an inhibitory effect on Hsp70 protein relative to control $(P=0.032)$. These investigations demonstrated identical, albeit less pronounced, results in the absence of LPS priming (Supplementary Figure S3).

\section{Effect of Glutamine on NF-kB Activation}

Next, we performed time-series $(1,2,4$, 8,24 and $48 \mathrm{~h}$ ) experiments to determine whether dose-dependent stimulation with Gln (0.5, 2.0 and $4.0 \mathrm{mM})$ attenuates NF-кB translocation into the nucleus. In nonstimulated conditions, Gln had no effect on activation of NF-kB (Figures 7A and B). However, treatment of cells with Gln was able to reverse the induction of NF- $\kappa \mathrm{B}$ promoted by $\mathrm{PfHz}$ and cause a dose- and time-dependent decrease in NF- $\kappa \mathrm{B}$ translocation into the nucleus (Figures 7A and B), demonstrating that Gln treatment can prevent the activation of NF- $\kappa \mathrm{B}$ induced by phagocytosis of hemozoin.

\section{Effect of Glutamine on Proinflammatory Mediators Modulated by HSP7O and NF- $\kappa$ B}

Previous studies demonstrated that Gln increases Hsp70 protein production, resulting in attenuation of NF- $\kappa B$ translocation into the nucleus and, consequently, reduced proinflammatory cytokine (IL-1 $\beta$, IL-6 and TNF- $\alpha$ ) production $(14,42,48)$. We and others have shown that dysregulation of these same
A

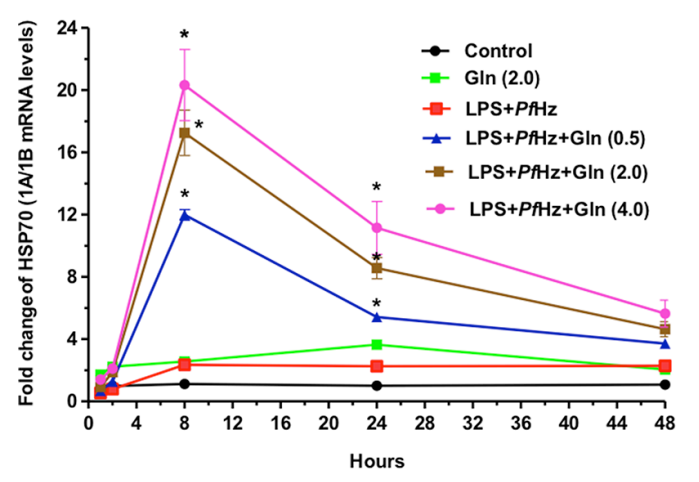

B

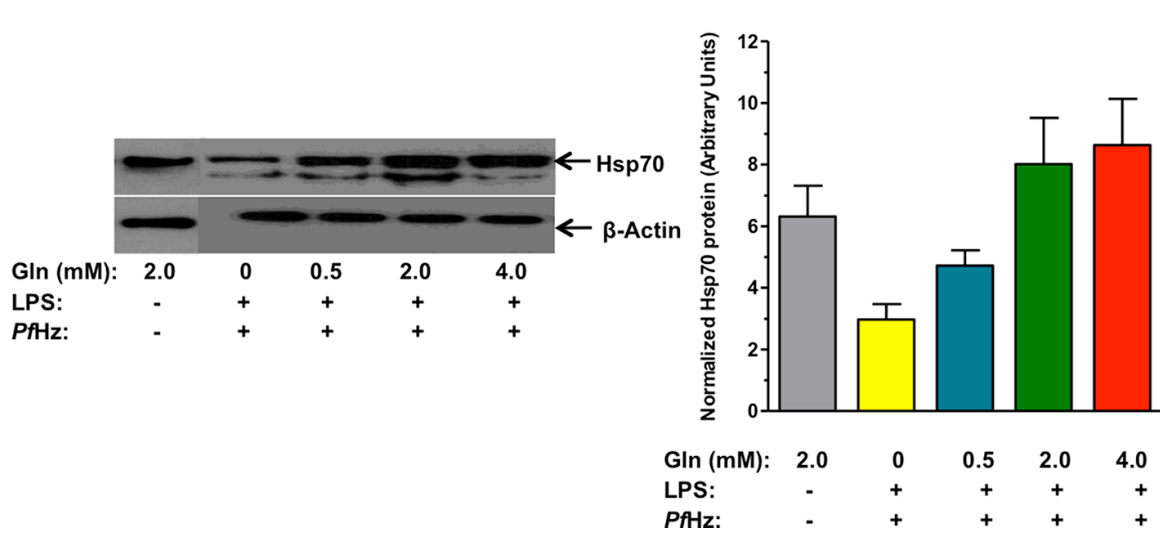

Figure 6. Effect of glutamine treatment on PfHz-mediated inhibition of HSP70. (A) Peripheral blood mononuclear cells $\left(2.5 \times 10^{6}\right)$ were incubated with LPS for $1 \mathrm{~h}$ prior to addition of $\mathrm{G} \ln (0.5,2.0$ and $4.0 \mathrm{mM}$, pretreated 30 min prior to adding PfHz) for different time points. Total RNA was isolated and gene expression analysis by qRT-PCR was performed to quantify the HSP70 ( $7 A+1 B$ ) transcripts, using TaqMan $^{\circledR}$ gene expression assays. $\beta$-actin was used as an endogenous control to normalize the data by the $\Delta \Delta C T$ method. Data represent average of individuals $\left(n=3\right.$ ) with each condition performed in triplicate (error bars represent SEM). ${ }^{*}$ indicates $P<0.05$ (one-way ANOVA) relative to LPS + PfHz treated cells. (B) Experiments performed as outlined in A showing the effect of Gln (0.5, 2.0 and 4.0 mM) on PfHz-mediated inhibition of Hsp70 assessed using immunoblotting at $24 \mathrm{~h}$. (C) Densitometry analysis was performed to quantify intensity of expression. Data shown after normalizing Hsp70 relative to $\beta$-actin $(n=3)$; error bars represent SEM. 
A

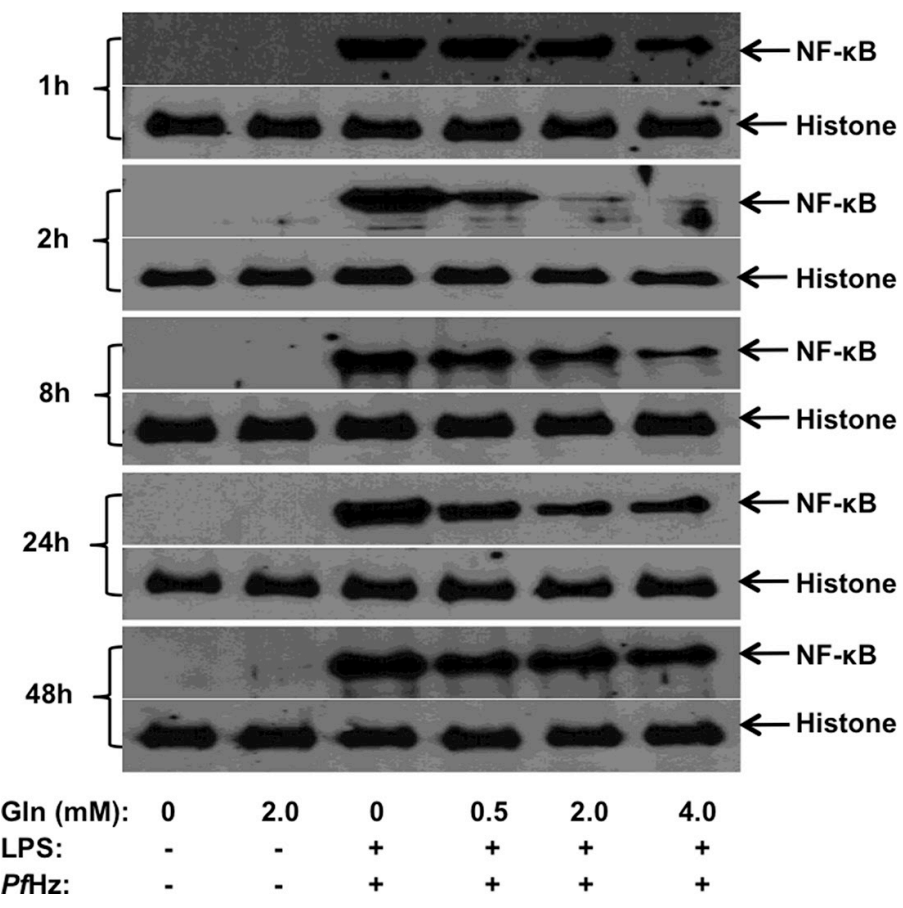

B

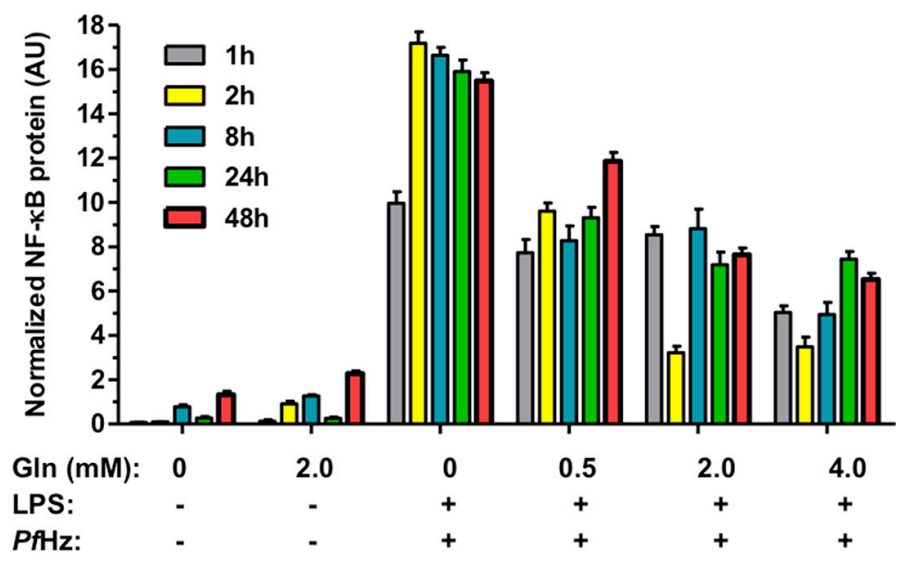

Figure 7. Effect of $\mathrm{PAHz}$ and glutamine on NF-kB translocation into the nucleus. (A) Peripheral blood mononuclear cells $\left(2.5 \times 10^{6}\right)$ were incubated with LPS for $1 \mathrm{~h}$ prior to the addition of $\mathrm{Gln}(0.5,2.0$ and $4.0 \mathrm{mM}$, pretreated $30 \mathrm{~min}$ prior to adding PfHz) for different time points. Nuclear extracts were prepared after harvesting cells at stipulated time points and equal amount of protein was loaded on 4-20\% SDS-PAGE to determine the amount of nuclear translocated NF-kB protein by immunoblotting. In addition, a nuclear marker (histone protein) was quantified to account for protein loading (control). (B) Densitometry analysis after normalizing the respective bands against histone $(n=3)$; error bars represent SEM.

proinflammatory mediators are also associated with clinical outcomes in children with malaria $(6,7,44,55)$. Since we found that Gln can overcome $\mathrm{PfHz}-$ induced suppression of Hsp70 and decrease NF- $\kappa$ B translocation into the nucleus, we determined whether Gln treatment could also prevent overexpression of IL-1 $\beta$, IL- 6 and TNF- $\alpha$. As shown in Figures 8A-C, stimulation of cells with LPS and $\mathrm{PfHz}$ caused a time-dependent increase in IL-1 $\beta$, IL- 6 and TNF- $\alpha$ transcript levels. Addition of Gln (0.5, 2.0 and $4.0 \mathrm{mM}$ ) dose-dependently reduced transcriptional expression of all three inflammatory mediators $(P<0.05$ for Gln treatments at all time points versus LPS + PfHz; Figures 8A-C). Collectively, these in vitro results demonstrate that Gln treatment rescues the inhibitory effect of PfHz-induced suppression of Hsp70 and overexpression of NF- $\mathrm{KB}-$ modulated proinflammatory cytokines that promote
SMA (reviewed in (6)). Consistent with our previous approach, additional investigations were performed using Gln and $\mathrm{PfHz}$ alone and in combination, without LPS stimulation. These experiments confirmed that the effect of Gln on cytokine responses in $\mathrm{PfHz}$-treated cells was independent of the priming (IL-1 $\beta$ $[P=0.022]$, TNF- $\alpha[P=0.002]$ and IL-6 $[P=0.007])$, and more robust responses generated by pretreatment with LPS (Supplementary Figures 4 and 5).

\section{DISCUSSION}

For more than a decade, we have been investigating the impact of altered immunity on the development of SMA. In particular, we have primarily focused on the innate immune response, because the infants and young children who develop SMA have not acquired robust antibody-mediated immunity, an important hallmark for protection against severe disease. Since our studies are conducted in a holoendemic P. falciparum transmission region of western Kenya, nearly all the children get repeated episodes of malaria prior to developing naturally acquired immunity.

Given that malaria pathogenesis is complex and, arguably, poorly understood, we sought to take an unbiased discovery approach. As such, we utilized the Illumina ${ }^{\circledR}$ HumanHT-12 v4 beadchip, which covers $>47,000$ transcripts, to catalogue global gene expression in children with malaria. To maximize the probability of finding important signals, we used the larger cohort of children to guide selection of malaria-infected individuals who were stratified into extreme phenotypes and compared the "sickest" individuals with the lowest $\mathrm{Hb}$ levels against the "healthiest" children with the highest $\mathrm{Hb}$ levels present during a malaria infection. 

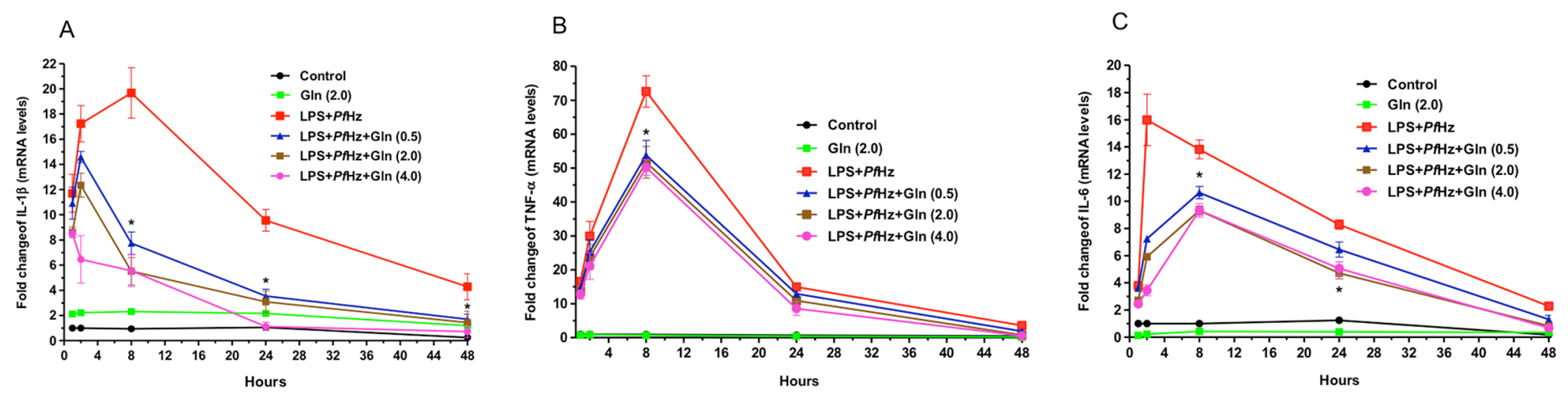

Figure 8. Effect of glutamine treatment on PfHz-mediated inhibition of proinflammatory mediators (IL-1 $\beta$, TNF- $\alpha$ and IL-6). Peripheral blood mononuclear cells $\left(2.5 \times 10^{6}\right)$ were incubated with LPS for $1 \mathrm{~h}$ prior to GIn treatment $(0.5,2.0$ and $4.0 \mathrm{mM}$, pretreated 30 min prior to adding PfHz) for different time points. Total RNA was isolated and gene expression analysis by qRT-PCR was performed to quantify the cytokine transcripts using TaqMan ${ }^{\circledR}$ gene expression assays. $\beta$-actin was used as an endogenous control to normalize the data by the $\Delta \Delta \mathrm{CT}$ method. Data represent average of individuals $(n=3)$ with each condition performed in triplicate (error bars represent SEM). ${ }^{*}$ indicates $P<0.05$ (one-way ANOVA) for GIn treatment relative to LPS + PfHz. (A) IL-1b mRNA fold change. (B) TNF- $\alpha$ mRNA fold change. (C) IL-6 mRNA fold change.

One of the genes that emerged as significantly different between the two groups in the transcriptomics experiments was HSPA1A. This finding warranted high priority for further exploration, since the heat-shock response via Hsp70 expression is an integral part of innate immunity that protects against inflammatory insults in response to cellular stress and infections (9,40,56-61). As such, the ability to induce functional HSP70 gene products represents an early cellular event that can dramatically impact subsequent immunological responses. Since the heat-shock response and, in particular, dysregulation in Hsp70 has not been reported as part of the host immune response to human malaria, we first sought to validate the global gene expression results by measuring HSPA1A and HSPA1B (cumulatively representing Hsp70) in additional malaria-infected individuals stratified into non-SMA and SMA. These experiments confirmed that HSP70 transcripts were significantly lower in children with severe disease, suggesting that dysregulation of Hsp70 may be associated with the pathogenesis of malaria, just as it is in other multifactorial diseases, including infectious diseases (e.g., severe sepsis, tuberculosis and leprosy), stress, and autoimmune and inflammatory diseases $(40,56,58,59,61-64)$.
To gain insight into the mechanism(s) by which HSP70 transcripts are suppressed in malaria, we stratified children with malaria into those with and without naturally acquired hemozoin in their circulating monocytes and neutrophils. The rationale for investigating hemozoin in circulating leukocytes as a source of lower HSP70 in children with severe disease was driven by experiments in our laboratory over the past decade. These investigations demonstrated that phagocytosis of $\mathrm{PfHz}$ is an important driver of dysregulation in cytokines, chemokines and effector molecule genes in children with SMA (reviewed in (6)). The ability of hemozoin to alter the innate immune response to malaria, and thereby enhance the anemia of inflammation, is supported by our findings showing that elevated levels of $\mathrm{PfHz}$ in circulating leukocytes are a significant predictor of SMA $(11,37,65)$. Stratification of children with malaria based on the presence and absence of $\mathrm{PfHz}$ in monocytes and neutrophils revealed significantly lower HSP70 transcripts in the presence of naturally acquired hemozoin, suggesting that phagocytosis of $\mathrm{PfHz}$ may be a potential source of altered HSP70 gene expression. It is unclear whether the effect is due to phagocytosis of $\mathrm{PfHz}$ or through molecules that are both conjugated with and produced by $\mathrm{PfHz}$. For example, $\mathrm{PfHz}$ carries and induces the cellular production of 15(S)hydroxyeicosatetraenoic acid (15-HETE) and 4-hydroxynonenal (4-HNE), both of which could act on blood cells in vivo and in vitro upon exposure to hemozoin $(66,67)$. Thus, it remains to be determined if the effects of $\mathrm{PfHz}$ on immune activation and the promotion of anemia are acting through hemozoin-promoted lipoperoxidation (68).

Prior to proceeding with additional investigations, we sought to determine whether the levels of HSP70 expression were associated with the primary clinical manifestations of SMA we established in holoendemic $P$. falciparum transmission regions: inefficient erythropoiesis leading to reduced $\mathrm{Hb}$ concentration $(4,7,39,69)$. There was a significant positive correlation between HSP70 transcripts and the reticulocyte production index and $\mathrm{Hb}$ levels, thus indicating that induction of a robust Hsp70 response is correlated with more efficient erythropoiesis and lower levels of anemia. This clinical finding in children with anemia is consistent with previous studies showing that Hsp70 is an important positive regulator of erythropoiesis $(70,71)$.

After establishing that reduced HSP70 transcripts were associated with 
enhanced disease severity in children with malaria, and that naturally acquired phagocytosis of hemozoin may be a driving factor in lower Hsp70, we performed a series of in vitro experiments to definitively establish this potential molecular mechanism. Incubation of cultured PBMCs with physiologically relevant concentrations of $\mathrm{PfHz}$ (37) caused a time-dependent decrease in the major HSP70 coding transcripts (HSPA1A and $H S P A 1 B)$ and Hsp70 protein, demonstrating that the transcriptional changes induced by $\mathrm{PfHz}$ affect functional Hsp70 protein levels. Previous studies from our group have shown increased Hsp70 in the context of elevated temperature in both animal models and cultured cells (45). As such, cultured PBMCs were exposed to $\mathrm{PfHz}$ at $42^{\circ} \mathrm{C}$. There was a 5.88 -fold increase in the expression of HSP70 transcripts due to heat-shock treatment by $24 \mathrm{~h}$ that was significantly reduced by the presence of $\mathrm{PfHz}$. Immunoblot experiments revealed that maximal PfHz-induced suppression of Hsp70 under heat-shock conditions was present by $48 \mathrm{~h}$, just as it was at $37^{\circ} \mathrm{C}$. This series of in vitro experiments demonstrate that phagocytosis of hemozoin can suppress Hsp70 transcripts and protein.

Accumulating evidence suggests that the protective (antiinflammatory) role of Hsp70 is mediated through downregulation of NF- $\kappa \mathrm{B}$, since NF- $\kappa \mathrm{B}$ activation and translocation into the nucleus promotes elevated proinflammatory mediators $(14,16-21,41,50,72,73)$.

Consistent with this notion, we and others have demonstrated that overexpression of Hsp70 protein blocks nuclear translocation of NF- $\kappa \mathrm{B}$ and thereby reduces proinflammatory mediator production (19-21,50). Although the role of Hsp70 in modulating the inflammatory response through interference with $\mathrm{NF}-\kappa \mathrm{B}$ activation has been shown in several diseases $(9,74-76)$, the link between Hsp70, NF-kB activation and cytokine production has not been established in human malaria. However, a number of previous in vitro studies have shown that hemozoin and other parasitic products induce the production of inflammatory mediators through NF- $\kappa \mathrm{B}$ activation (16). Results presented here show that $\mathrm{PfHz}$ induces rapid translocation of NF-кB into the nucleus with peak levels by $8 \mathrm{~h}$. In addition, after induction of Hsp70 with elevated temperature $\left(42^{\circ} \mathrm{C}\right), \mathrm{PfHz}$ remained capable of causing NF- $\kappa \mathrm{B}$ activation, although to a lesser extent due to enhanced Hsp70 expression.

Reduced Gln levels have been associated with numerous adverse clinical outcomes, such as increased coinfections; sepsis; inflammatory, epithelial, hematopoietic and exercise-induced permeability, organ injury, etc. $(23,28,30,31,77,78)$. Although low circulating Gln concentrations $(<420 \mu \mathrm{mol} / \mathrm{L})$ are associated with increased mortality in critically ill adults $(30,52)$, there is little information available about the relationship between plasma Gln and morbidity and mortality in severely ill children. Several studies suggest that similar characteristics for Gln metabolism may exist between adult and pediatric populations. For example, severely ill neonates have low plasma Gln concentrations $(79,80)$. It was also recently shown that low plasma Gln levels in critically ill children are associated with a higher incidence of multiple organ failure and longer duration of stay in the pediatric intensive care unit (53). Results presented here extend these previous investigations by demonstrating that children with SMA have significantly lower plasma Gln levels, and that low circulating Gln concentrations are associated with a highly significant increase in the risk of developing severe malaria. Lower levels of circulating Gln have also been reported in Ghanaian children with acute falciparum malaria compared with control cases (81). However, our finding that low levels of Gln in children with malaria are associated with enhanced disease severity appears to differ from a previous finding in Gabonese children with malaria, in which plasma Gln concentrations were higher in children with severe versus moderate disease, and highest in those who died compared with those who survived (82). Although we did not directly compare the Gln levels in children who died of severe malaria, since there were only two deaths in this study population, potential differences across the studies may be due to the case definition of severe malaria. For example, the Gabonese study included a definition of severe disease defined by one or more of the following: Blantyre coma score $\leq 2$, repeated witnessed convulsions ( $\geq 3$ ), lactate $\geq 5 \mathrm{mmol} / \mathrm{L}$, glucose $\leq 2.2 \mathrm{mmol} / \mathrm{L}$ and severe anemia $(\mathrm{Hb}<5.0 \mathrm{~g} / \mathrm{dL}$ or hematocrit $<15 \%)$, whereas the definition of severe disease in our study included only children with SMA $(\mathrm{Hb}<5.0 \mathrm{~g} / \mathrm{dL}$ in the presence of any density parasitemia). The definition of severe disease used in the current study was based on the fact that cerebral malaria is exceedingly rare in the region (83). This distinction may be important in the context of recent findings in murine experimental cerebral malaria, in which administration late in the infection of a glutamine analog, 6-diazo-5-

oxo-L-norleucine, which broadly inhibits Gln metabolism, rescues mice from the manifestations of severe disease, including blood-brain barrier dysfunction, brain swelling and hemorrhaging, and accumulation of parasite-specific CD8 + effector T cells and infected red blood cells in the brain (84). It remains to be determined if Gln supplementation as an adjunctive treatment in the context of antimalarial chemotherapy provides differing clinical outcomes in children with cerebral malaria versus those with SMA. In any event, data presented in the current cohort of children clearly show that low circulating Gln levels are associated with more severe disease.

Although the physiological actions of Gln are diverse, numerous studies show that therapeutic supplementation with Gln has beneficial effects through the promotion of enhanced HSP expression (25-28). Moreover, Gln-mediated induction of the heat-shock response is an important part of the innate immune response, since Gln is critical for protection and recovery from tissue injury and stress-related inflammation $(23,28,76,85)$. 
Additional studies have shown that macrophages require high levels of Gln to successfully produce inflammatory mediators as part of the innate immune response for protection against intracellular pathogens (86). Consistent with this notion, results here show that there is a significant positive association between plasma Gln concentrations and HSP70 transcript levels measured in circulating white blood cells from children with malaria. Although cellular and molecular mechanisms involved in Gln-induced HSP70 upregulation remain largely unknown, previous studies have shown that Gln increases the amount of unphosphorylated HSF-1 in the nucleus, the main regulator of the heat-stress response $(23,24)$. Recent studies also suggest that activation of HSP70 may be mediated via O-glycosylation, nuclear translocation and transcriptional activation of Sp1 and HSF-1, as well as activation of the PI3-K/Akt pathway $(87,88)$.

In a series of in vitro experiments presented here, we demonstrate that addition of Gln can overcome suppression of HSP70 transcripts and protein induced by $\mathrm{PfHz}$ in a dose- and timedependent manner. We further show that the effect of Gln appears to be mediated through a dose- and time-dependent prevention of NF- $\kappa \mathrm{B}$ translocation into the nucleus, a process that we demonstrate downregulates HSP70. Previous studies have shown that Hsp70 is an important protein for regulating inflammatory mediator production of disease-promoting cytokines, such as IL-1 $\beta$, IL-6 and TNF- $\alpha$ (42). Results presented here extend these previous findings by showing that Gln can prevent overproduction of these same cytokines in PfHz-treated cells. This is extremely encouraging, since we and others have shown that elevated levels of these proinflammatory mediators are associated with enhanced disease severity in children with malaria $(6,7,44)$.

\section{CONCLUSION}

The current study demonstrates that children with SMA have significantly reduced intracellular Hsp70 levels that appear to result from phagocytosis of $\mathrm{PfHz}$, a process that we show enhances translocation of NF- $\kappa \mathrm{B}$ to the nucleus. Moreover, children with SMA have significantly reduced circulating Gln levels that are associated with increased susceptibility to SMA. Importantly, we show that treatment of PBMCs with Gln attenuates the inhibitory effect of $\mathrm{PfHz}$-induced suppression of Hsp70, nuclear translocation of NF- $\kappa \mathrm{B}$ and overexpression of proinflammatory cytokines that are associated with adverse clinical outcomes in children with malarial anemia. Taken together, the results presented here describe the molecular mechanisms responsible for decreased Hsp70 in children with SMA, and support the feasibility of future studies using Gln supplementation as a therapeutic option for the treatment of SMA.

\section{ACKNOWLEDGEMENTS}

The authors gratefully acknowledge the assistance of the University of New Mexico/Kenya Medical Research Institute (KEMRI) team (Nicholas Otieno Ondiek, Elly Ochieng Munde, Vincent Odhiambo Otieno, Angela Achieng Omondi, Lily Kisia, Anne A Ong'ondo, Chrispine Wasonga Ochieng, Everlyne A Modi, Joan L A Ochieng, Jacob Oyoko Odeny, Joseph Oduor, Martin Ogalo, Moses Ebungure, Moses Lokorkeju, Rodney B Mongare, Stella Mariz Akinyi Oloo and Vincent Omanje). We are also grateful to all of the parents, guardians and children who participated in the study. The authors also thank the director of KEMRI for approving publication of the manuscript.

This work was supported by National Institutes of Health Research Grants R01AI51305 and D43TW05884 (DJP). This project was also supported (in part) by the National Center for Research Resources and the National Center for Advancing Translational Sciences of the National Institutes of Health through grant no. UL1TR001449 (PK). The content is solely the responsibility of the authors and does not necessarily represent the official views of the NIH.

\section{DISCLOSURE}

The study was approved by the ethical and scientific review committees at the University of Pittsburgh, the University of New Mexico and the Kenya Medical Research Institute. A portion of this work was presented at the sixth Multilateral Initiative on Malaria Pan-African Malaria Conference, held at the International Convention Centre, Durban, South Africa, October 6-11, 2013, titled "Glutamine ameliorates hemozoin-mediated suppression of heat shock protein 70 and over-expression of proinflammatory cytokines in peripheral blood."

\section{REFERENCES}

1. World Health Organization. (2015) World Malaria Report.

2. Breman JG, Egan A, Keusch GT. (2001) The intolerable burden of malaria: a new look at the numbers. Am. J. Trop. Med. Hyg. 64(1-2 Suppl):iv-vii.

3. Ong'echa JM, et al. (2006) Parasitemia, anemia, and malarial anemia in infants and young children in a rural holoendemic Plasmodium falciparum transmission area. Am. J. Trop. Med. Hyg. 74(3):376-85.

4. Were T, et al. (2006) Suppression of RANTES in children with Plasmodium falciparum malaria. Haematologica. 91(10):1396-99.

5. Fendel R, et al.(2010) Hemolysis is associated with low reticulocyte production index and predicts blood transfusion in severe malarial anemia. PLoS One. 5(4):e10038.

6. Perkins DJ, et al. (2011) Severe malarial anemia: innate immunity and pathogenesis. Int. J. Biol. Sci. 7(9):1427-42.

7. Ong'echa JM, et al. (2011) Identification of inflammatory biomarkers for pediatric malarial anemia severity using novel statistical methods. Infect. Immun. 79(11):4674-80.

8. McCullough J. (2014) RBCs as targets of infection. Hematology Am. Soc. Hematol. Educ. Program. (1):404-09.

9. Moseley PL. (1998) Heat shock proteins and the inflammatory response. Ann. N.Y. Acad. Sci.. 856: 206-13.

10. Casals-Pascual C, et al. (2006) Suppression of erythropoiesis in malarial anemia is associated with hemozoin in vitro and in vivo. Blood. 108(8):2569-77.

11. Awandare GA, et al. (2007) Role of monocyteacquired hemozoin in suppression of macrophage migration inhibitory factor in children with severe malarial anemia. Infect. Immun. 75(1):201-10.

12. Were T, et al. (2009) Naturally acquired hemozoin by monocytes promotes suppression of RANTES in children with malarial anemia through an IL-10-dependent mechanism. Microbes Infect. 11(8-9):811-19. 
13. Shio MT, et al. (2010) Innate inflammatory response to the malarial pigment hemozoin. Microbes Infect. 12(12-13):889-99.

14. Giribaldi G, et al. (2010) Involvement of inflammatory chemokines in survival of human monocytes fed with malarial pigment. Infect. Immun. 78(11):4912-21.

15. Polimeni M, et al. (2012) Haemozoin induces early cytokine-mediated lysozyme release from human monocytes through p38 MAPK- and NF-kappaB-dependent mechanisms. PLoS One. 7(6): e39497.

16. Punsawad C. (2013) Effect of malaria components on blood mononuclear cells involved in immune response. Asian Pac. J. Trop. Biomed. 3(9):751-56.

17. Tieri $\mathrm{P}$, et al. (2012) Charting the NF-kappaB pathway interactome map. PLoS One. 7(3):e32678.

18. Basak S, Behar M, Hoffmann A. (2012) Lessons from mathematically modeling the NF-kappaB pathway. Immunol. Rev. 246(1):221-38.

19. Hinz M, et al. (1999) NF-kappaB function in growth control: regulation of cyclin D1 expression and G0/G1-to-S-phase transition. Mol. Cell. Biol. 19(4):2690-98.

20. Yao YW, et al. (2011) Lipopolysaccharide pretreatment protects against ischemia/reperfusion injury via increase of HSP70 and inhibition of NF-kappaB. Cell Stress Chaperones. 16(3):287-96.

21. Shi Y, et al. (2006) The inhibition of LPS-induced production of inflammatory cytokines by HSP70 involves inactivation of the NF-kappaB pathway but not the MAPK pathways. Shock. 26(3):277-84.

22. Dokladny K, et al. (2010) LPS-induced cytokine levels are repressed by elevated expression of HSP70 in rats: possible role of NF-kappaB. Cell Stress Chaperones. 15(2):153-63.

23. Akagi R, et al. (2013) Glutamine protects intestinal barrier function of colon epithelial cells from ethanol by modulating Hsp70 expression. Pharmacology. 91(1-2):104-11.

24. Dokladny K, et al. (2013) Regulatory coordination between two major intracellular homeostatic systems: heat shock response and autophagy. J. Biol. Chem. 288(21):14959-972.

25. Wischmeyer PE, et al. (2003) Glutamine attenuates tumor necrosis factor-alpha release and enhances heat shock protein 72 in human peripheral blood mononuclear cells. Nutrition. 19(1):1-6.

26. Singleton KD, et al. (2005) Glutamine attenuates lung injury and improves survival after sepsis: role of enhanced heat shock protein expression. Crit. Care Med. 33(6):1206-13.

27. Singleton KD, Wischmeyer PE. (2006) Oral glutamine enhances heat shock protein expression and improves survival following hyperthermia. Shock. 25(3):295-99.

28. Xue H, Sufit AJ, Wischmeyer PE. (2011) Glutamine therapy improves outcome of in vitro and in vivo experimental colitis models. J. Parenter. Enteral Nutr. 35(2):188-97.
29. Chen QH, et al. (2014) The effect of glutamine therapy on outcomes in critically ill patients: a meta-analysis of randomized controlled trials. Crit. Care. 18(1):R8.

30. Oudemans-van Straaten, HM, et al. (2001) Plasma glutamine depletion and patient outcome in acute ICU admissions. Intensive Care Med. 27(1):84-90.

31. Dechelotte P, et al. (2006) L-alanyl-L-glutamine dipeptide-supplemented total parenteral nutrition reduces infectious complications and glucose intolerance in critically ill patients: the French controlled, randomized, double-blind, multicenter study. Crit. Care Med. 34(3):598-604.

32. Mazloomi E, et al. (2011) Synergistic effects of glutamine and ciprofloxacin in reduction of Pseudomonas aeruginosa-induced septic shock severity. Int. Immunopharmacol. 11(12):2214-19.

33. Beier JC, et al. (1994) Plasmodium falciparum incidence relative to entomologic inoculation rates at a site proposed for testing malaria vaccines in western Kenya. Am. J. Trop. Med. Hyg. 50(5):529-36.

34. World Health Organization. (2000) Severe falciparum malaria. World Health Organization, Communicable Diseases Cluster. Trans. R. Soc. Trop. Med. Hyg. 94:S1-90.

35. Were T, et al. (2011) Bacteremia in Kenyan children presenting with malaria. J. Clin. Microbiol. 49(2):671-76.

36. Keller CC, et al. (2004) Reduced peripheral PGE2 biosynthesis in Plasmodium falciparum malaria occurs through hemozoin-induced suppression of blood mononuclear cell cyclooxygenase-2 gene expression via an interleukin-10-independent mechanism. Mol. Med. 10(1-6):45-54.

37. Keller CC, et al. (2004) Elevated nitric oxide production in children with malarial anemia: hemozoin-induced nitric oxide synthase type 2 transcripts and nitric oxide in blood mononuclear cells. Infect. Immun. 72(8):4868-73.

38. Chomczynski P, Sacchi N. (1987) Single-step method of RNA isolation by acid guanidinium thiocyanate-phenol-chloroform extraction. Anal. Biochem. 162(1):156-59.

39. Keller CC, et al. (2009) Suppression of a novel hematopoietic mediator in children with severe malarial anemia. Infect. Immun. 77(9):3864-71.

40. Balog A, et al. (2004) Tumour necrosis factoralpha and heat-shock protein 70-2 gene polymorphisms in a family with rheumatoid arthritis. Acta Microbiol. Immunol. Hung. 51(3):263-69.

41. Voegeli TS, et al. (2008) Heat shock proteins 27 and 70 regulating angiotensin II-induced NF-kappaB: a possible connection to blood pressure control? Appl. Physiol. Nutr. Metab. 33(5):1042-49.

42. Borges TJ, et al. (2012) The anti-inflammatory mechanisms of Hsp70. Front. Immunol. 3:95.

43. Anyona SB, et al. (2012) Reduced systemic bicyclo-prostaglandin-E2 and cyclooxygenase-2 gene expression are associated with inefficient erythropoiesis and enhanced uptake of monocytic hemozoin in children with severe malarial anemia. Am. J. Hematol. 87(8):782-89.

44. McDevitt MA, et al. (2004) The anemia of malaria infection: role of inflammatory cytokines. Curr. Hematol. Rep. 3(2):97-106.

45. Dokladny K, et al. (2006) Induction of physiological thermotolerance in MDCK monolayers: contribution of heat shock protein 70. Cell Stress Chaperones. 11(3):268-75.

46. Cambos M, et al. (2010) The IL-12p70/IL-10 interplay is differentially regulated by free heme and hemozoin in murine bone-marrow-derived macrophages. Int. J. Parasitol. 40(9):1003-12.

47. Nti BK, et al. (2005) Stage-specific effects of Plasmodium falciparum-derived hemozoin on blood mononuclear cell TNF-alpha regulation and viral replication. AIDS. 19(16):1771-80.

48. Zhu J, Krishnegowda G, Gowda DC. (2005) Induction of proinflammatory responses in macrophages by the glycosylphosphatidylinositols of Plasmodium falciparum: the requirement of extracellular signal-regulated kinase, p38, c-Jun $\mathrm{N}$-terminal kinase and NF-kappaB pathways for the expression of proinflammatory cytokines and nitric oxide. J. Biol. Chem. 280(9):8617-27.

49. Jaramillo M, Godbout M, Olivier M. (2005) Hemozoin induces macrophage chemokine expression through oxidative stress-dependent and -independent mechanisms. J. Immunol. 174(1):475-84.

50. Senf SM, et al. (2008) Hsp70 overexpression inhibits NF-kappaB and Foxo3a transcriptional activities and prevents skeletal muscle atrophy. FASEB J. 22(11):3836-45.

51. Kee C, Pham K, Waterer GW, Temple SE (2008) Genetic variation in heat shock protein 70 is associated with septic shock: narrowing the association to a specific haplotype. Int. J. Immunogenet. 35(6):465-73.

52. Rodas PC, et al. (2012) Glutamine and glutathione at ICU admission in relation to outcome. Clin. Sci. (Lond.) 122(12):591-97.

53. Ekmark L, et al. (2015) Plasma glutamine deficiency is associated with multiple organ failure in critically ill children. Amino Acids. 47(3):535-42.

54. Grossman BJ, et al. (2002) Temporal and mechanistic effects of heat shock on LPS-mediated degradation of IkappaBalpha in macrophages. Inflammation. 26(3):129-37.

55. Clark TG, et al. (2009) Tumor necrosis factor and lymphotoxin-alpha polymorphisms and severe malaria in African populations. J. Infect. Dis. 199(4):569-75.

56. Schroder O, et al. (2003) Heat shock protein 70 genotypes HSPA1B and HSPA1L influence cytokine concentrations and interfere with outcome after major injury. Crit. Care Med. 31(1):73-79.

57. Otaka M, Odashima M, Watanabe S. (2006) Role of heat shock proteins (molecular chaperones) in intestinal mucosal protection. Biochem. Biophys. Res. Commun. 348(1):1-5. 
58. Karoly E, et al. (2007) Heat shock protein 72 (HSPA1B) gene polymorphism and Toll-like receptor (TLR) 4 mutation are associated with increased risk of urinary tract infection in children. Pediatr. Res. 61(3):371-74.

59. Gombos T, et al. (2008) Interaction of serum $70-\mathrm{kDa}$ heat shock protein levels and HspA1B $(+1267)$ gene polymorphism with disease severity in patients with chronic heart failure. Cell Stress Chaperones. 13(2):199-206.

60. Liang M, et al. (2009) Different effect of glutamine on macrophage tumor necrosis factor-alpha release and heat shock protein 72 expression in vitro and in vivo. Acta Biochim. Biophys. Sin. (Shanghai). 41(2):171-77.

61. Furnrohr BG, et al. (2010) Polymorphisms in the Hsp70 gene locus are genetically associated with systemic lupus erythematosus. Ann. Rheum. Dis. 69(11):1983-89.

62. Rajalingam R, Mehra NK, Singal DP. (2000) Polymorphism in heat-shock protein 70-1 (HSP70-1) gene promoter region and susceptibility to tuberculoid leprosy and pulmonary tuberculosis in Asian Indians. Indian J. Exp. Biol. 38(7): 658-62.

63. Pae CU, et al. (2005) Polymorphisms of heat shock protein 70 gene (HSPA1A, HSPA1B and HSPA1L) and schizophrenia. Neurosci. Res. 53(1):8-13.

64. He M, et al. (2009) Functional SNPs in HSPA1A gene predict risk of coronary heart disease. PLoS One. 4(3):e4851.

65. Awandare GA, et al. (2006) A macrophage migration inhibitory factor promoter polymorphism is associated with high-density parasitemia in children with malaria. Genes Immun. 7(7):568-75.

66. Skorokhod OA, et al. (2004) Hemozoin (malarial pigment) inhibits differentiation and maturation of human monocyte-derived dendritic cells: a peroxisome proliferator-activated receptor-gamma-mediated effect. J. Immunol. 173(6):4066-74.

67. Skorokhod OA, et al. (2010) Inhibition of erythropoiesis in malaria anemia: role of hemozoin and hemozoin-generated 4-hydroxynonenal. Blood. 116(20):4328-37.

68. Schwarzer E, Arese P, Skorokhod OA. (2015) Role of the lipoperoxidation product 4-hydroxynonenal in the pathogenesis of severe malaria anemia and malaria immunodepression. Oxid. Med. Cell Longev. 2015:638416.

69. Ouma C, et al. (2010) A novel functional variant in the stem cell growth factor promoter protects against severe malarial anemia. Infect. Immun. 78(1):453-60.

70. Ribeil JA, et al. (2007) Hsp70 regulates erythropoiesis by preventing caspase-3-mediated cleavage of GATA-1. Nature. 445(7123):102-05.

71. Frisan E, et al. (2012) Defective nuclear localization of Hsp70 is associated with dyserythropoiesis and GATA-1 cleavage in myelodysplastic syndromes. Blood. 119(6):1532-42.

72. Grossman BJ, et al. (2002) Phosphatase inhibition leads to activation of IkappaB kinase in murine macrophages. Biochem. Biophys. Res. Commun. 297(5):1264-69.

73. Odashima M, et al. (2006) Zinc L-carnosine protects colonic mucosal injury through induction of heat shock protein 72 and suppression of NF-kappaB activation. Life Sci. 79(24):2245-50.

74. Prohászka Z. (2004) Immunological aspects of heat-shock proteins-the optimum stress of life. Mol. Immunol. 41(1):29-44.

75. Amorim F, et al. (2010) Effects of whole-body heat acclimation on cell injury and cytokine responses in peripheral blood mononuclear cells. Eur. J. Appl. Physiol. 111(8):1609-18.

76. Feng JY. (2010) Alteration and role of heat shock proteins in acute pancreatitis. J. Dig. Dis. 11(5):277-83.

77. de Oliveira GP, et al. (2014) Intravenous glutamine administration reduces lung and distal organ injury in malnourished rats with sepsis. Shock. 41(3):222-32.

78. Zuhl MN, et al. (2014) Effects of oral glutamine supplementation on exercise-induced gastrointestinal permeability and tight junction protein expression. J. Appl. Physiol. 116(2):183-91.

79. Becker RM, et al. (2000) Reduced serum amino acid concentrations in infants with necrotizing enterocolitis. J. Pediatr. 137(6):785-93.

80. Oladipo OO, et al. (2011) Impact of premature birth and critical illness on neonatal range of plasma amino acid concentrations determined by LC-MS/MS. Mol. Genet. Metab. 104(4):476-79.

81. Cowan G, et al. (1999) Plasma glutamine levels and falciparum malaria. Trans. R. Soc. Trop. Med. Hyg. 93(6):616-18.

82. Planche T, et al. (2002) Plasma glutamine and glutamate concentrations in Gabonese children with Plasmodium falciparum infection. QJM. 95(2):89-97.

83. O'Meara WP, et al. (2008) Effect of a fall in malaria transmission on morbidity and mortality in Kilifi, Kenya. Lancet. 372(9649):1555-62.

84. Gordon EB, et al. (2015) Targeting glutamine metabolism rescues mice from late-stage cerebral malaria. Proc. Natl. Acad. Sci. U.S.A. 112(42):13075-080.

85. Morrison AL, et al. (2006) Glutamine's protection against cellular injury is dependent on heat shock factor-1. Am. J. Physiol. Cell Physiol. 290(6):C1625-32.

86. Meador BM, Huey KA. (2009) Glutamine preserves skeletal muscle force during an inflammatory insult. Muscle Nerve. 40(6):1000-07.

87. Gong J, Jing L. (2011) Glutamine induces heat shock protein 70 expression via O-GlcNAc modification and subsequent increased expression and transcriptional activity of heat shock factor-1. Minerva Anesthesiol. 77(5):488-95.

88. Niederlechner S, Baird C, Wischmeyer PE. (2013) P38MAP kinase, but not phosphoinositol-3 kinase, signal downstream of glutamine-mediated fibronectin-integrin signaling after intestinal injury. Nutr. J. 12(1):88.
Cite this article as: Kempaiah P, et al. (2016) Reduced Hsp70 and glutamine in pediatric severe malaria anemia: Role of hemozoin in suppressing Hsp70 and NF-кB activation. Mol. Med. 22:570-84. 